\title{
Spectral Response Patterns of Auditory Cortex Neurons to Harmonic Complex Tones in Alert Monkey (Macaca mulatta)
}

\author{
DIETRICH W. F. SCHWARZ AND R. W. WARD TOMLINSON \\ The Rotary Hearing Centre, Division of Otolaryngology and Department of Physiology, \\ University of British Columbia, Vancouver, British Columbia, V6T 2B5, Canada
}

\section{SUMMARY AND CONCLUSIONS}

1. The auditory cortex in the superior temporal region of the alert rhesus monkey was explored for neuronal responses to pure and harmonic complex tones and noise. The monkeys had been previously trained to recognize the similarity between harmonic complex tones with and without fundamentals. Because this suggested that they could perceive the pitch of the lacking fundamental similarly to humans, we searched for neuronal responses relevant to this perception.

2. Combination-sensitive neurons that might explain pitch perception were not found in the surveyed cortical regions. Such neurons would exhibit similar responses to stimuli with similar periodicities but differing spectral compositions. The fact that no neuron with responses to a fundamental frequency responded also to a corresponding harmonic complex missing the fundamental indicates that cochlear distortion products at the fundamental may not have been responsible for missing fundamentalpitch perception in these monkeys.

3. Neuronal responses can be expressed as relatively simple filter functions. Neurons with excitatory response areas (tuning curves) displayed various inhibitory sidebands at lower and/or higher frequencies. Thus responses varied along a continuum of combined excitatory and inhibitory filter functions.

4. Five elementary response classes along this continuum are presented to illustrate the range of response patterns.

5 . "Filter $(F)$ neurons" had little or no inhibitory sidebands and responded well when any component of a complex tone entered its pure-tone receptive field. Bandwidths increased with intensity. Filter functions of these neurons were thus similar to cochlear nerve-fiber tuning curves.

6. "High-resolution filter (HRF) neurons" displayed narrow tuning curves with narrowband widths that displayed little growth with intensity. Such cells were able to resolve up to the lowest seven components of harmonic complex tones as distinct responses. They also responded well to wideband stimuli.

7. "Fundamental $\left(F_{0}\right)$ neurons" displayed similar tuning bandwidths for pure tones and corresponding fundamentals of harmonic complexes. This response pattern was due to lower inhibitory sidebands. Thus these cells cannot respond to missing fundamentals of harmonic complexes. Only physically present components in the pure-tone receptive field would excite such neurons.

8. Cells with no or very weak responses to pure tones or other narrowband stimuli responded well to harmonic complexes or widcband noise. Such cells are classified as "wideband (WB) neurons".

9. "Narrowband (NB) neurons" responded well to pure tones or other narrowband stimuli but not to harmonic complexes or wideband noises.

10. Neurons with high-frequency inhibitory sidebands, with more than one best-frequency $(\mathrm{BF})$ region or other complicated response patterns have also been observed.
11. Neuronal selectivity for various tones with distinct pitches has never been reported. It is unlikely that pitch is tonotopically represented in A 1 and other surveyed cortical regions. It remains to be determined if tonal pitch depends on large scale parallel processing in the principal auditory fields or a topographic representation in different cortical areas.

\section{INTRODUCTION}

The auditory cortex of mammals has been commonly reported to be tonotopically organized (Brugge and Reale 1985; Kiang and Goldstein 1959; Merzenich and Brugge 1973; Suga et al. 1983). Thus the cortical surface of several auditory fields can be subdivided into contiguous isofrequency bands, each being optimally excited by a narrowband of pure-tone frequencies. This organization already exists in the cochlea where there is an orderly array of neurons tuned to increasing frequencies along basilar membrane from the apex to the base. At the cortical level an organization of higher order might be expected. A reasonable hypothesis is that neurons might extract features of biological significance from stimuli that normally lead to a behavioral response. Such stimuli include vocalizations used for intraspecific communication as well as sound produced by predators and prey. Most biologically relevant sounds (e.g., vocalization) contain periodic (tonal) and nonperiodic (noise) elements. The periodic elements generally consist of harmonic series of sinusoidal components, that is, component frequencies are integer multiples of the fundamental frequency. Recognition of sound identity (e.g., a vowel in human speech or a howl produced by monkeys) depends on the amplitude distribution of the components along the frequency coordinate. Thus a large variety of voiced or other periodic sounds can be based on the same harmonic series. A change in the period of the sound wave-form corresponds to a proportional frequency change of all harmonic spectral components and is perceived as change in pitch (American Standards Association 1960). If, for example, a particular monkey howl or human vowel is presented at different pitches, the amplitude distribution along the frequency axis may remain constant although the frequencies of all components change. The pitch of the entire harmonic complex is identical to the pitch of a pure sine wave at the fundamental frequency, even if the fundamental and other components are missing (phenomenon of the missing fundamental). Harmonic complexes with clearly defined pitches are perceived as tones. Because missing fundamental pitch perception has 
been reported for humans (de Boer 1976), cats (Whitfield 1980), birds (Cynx 1986), and the same monkeys serving as experimental animals in the present study (Tomlinson and Schwarz 1988), tonal pitch may be perceived by a wide variety of higher vertebrates.

Complex-tone pitch does not simply result from distortions of sound in the cochlea, as originally assumed by von Helmholz (1862), but to a large extent from central processing, because the missing fundamental is heard when different upper harmonics are presented to each ear (Houtsma and Goldstein 1972). Pitch could be calculated from the relative separation of spectral components (along the frequency axis) or the periodicity (along the time axis) of the complex tone. It has, correspondingly, been proposed that pitch is extracted centrally either in the time domain (period analysis) (de Boer 1976; Langner 1983) or in the frequency domain (spectral analysis) (Goldstein 1973; Terhardt 1972; Wightman 1973). In either case harmonic complex tones are particularly useful for the exploration of cortical topography: if there was a tonotopical array of perceived pitch, neurons should be selective for the sound period, or spectral component separation, rather than frequency. If, on the other hand, the topographic display simply reflects frequency, the principle for organization would more likely be the innervation pattern of the cochlea. Although most investigators of auditory cortex appear to tacitly assume such a cochleotopic organization, there are also classical (Penfield and Rasmussen 1950) and modern (Pantev et al. 1989) proposals for a truly tonotopic organization with cortical arrays of pitch rather than frequencies.

Because much biologically relevant sound has a harmonic structure, it seems reasonable to expect neurons sensitive to combinations of harmonic components, that is, to definable pitches somewhere in cortex. Similar combination sensitivity for various components of echo location calls has been found in the cortex of the mustached bat (Suga 1984; Suga et al. 1979, 1983; Tsuzuki and Suga 1988). Previous single-unit studies employing stimuli with harmonic spectra were limited to the sensitivity of cortical neurons to temporal parameters of the stimulus, because components could not be independently manipulated [amplitude modulated tones (Schreiner and Urbas 1988)], [repetitive click trains (de Ribaupierre et al. 1972)]. Experiments using interrupted noise found no representation of stimulus period in the cat (Kiang and Goldstein 1959). This study attempts to determine how the results of either temporal or spectral processing at lower levels might be represented in the auditory cortex of alert monkeys. A systematic investigation of single neurons with harmonic complex stimuli should be able to resolve the question of a topographical representation of pitch in the auditory cortex.

\section{METHODS}

The subjects were three juvenile female rhesus monkeys ( $\mathrm{Ma}$ caca mulatta), $3^{1 / 2-4} \frac{1}{1} / 2$ yr old, weighing between 4.5 and $6.5 \mathrm{~kg}$. All subjects $(M 2, M 3$, and $M 4)$ had been previously trained in a psychophysical pitch matching task, and there was evidence that at least two of them (M2 and $M 3$ ) could perceive the missing fundamental (Tomlinson and Schwarz 1988).

\section{Acoustic stimuli}

A typical group of tonal stimuli for a given fundamental frequency is illustrated in Fig. 1. Usually pure tones (solid sine wave) were compared with complex tones consisting of the sum of either all lowest eight components of a harmonic series (2nd row from bottom) or the sum of several higher components not including the fundamental and other low components (for example, components 3-8, bottom row in Fig. 1). Upper harmonic components (shown as dotted curves in Fig. 1) were not presented in isolation. Line spectra of these stimuli are shown to the right (Fig. 1). All three stimulus types (solid curves) have the same period $\mathrm{P}$ and are perceived with the same pitch (corresponding to $100 \mathrm{~Hz}$ in this example). The corresponding frequency $1 / \mathrm{P}$ was the parameter systematically changed along the ordinates in Figs. 2, 4, 5, 7, 9, 10 , and 11.

Pure- and complex-tone stimuli were generated by a custombuilt digital synthesizer with a 16-bit digital-to-analogue converter (DAC) driven at $72 \mathrm{kHz}$. The signal was fed into a 12-bit multiplying DAC and through an eight-pole elliptical filter with a cut-

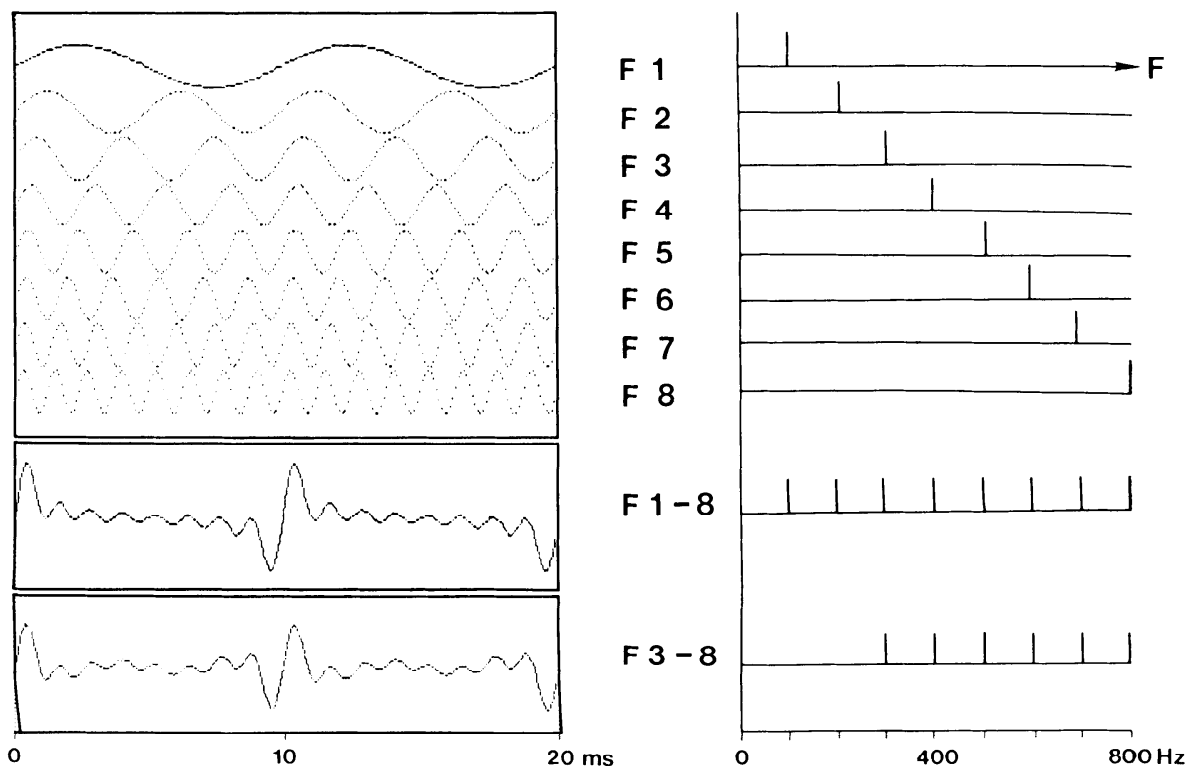

FIG. 1. Tonal stimuli used are shown as solid curves in the time domain to the left. Their frequency composition $(F)$ is illustrated in line spectra to the right. Dotted sine waves represent upper harmonics that were not presented in isolation but only as components of complexes. Second frame shows the harmonic complex composed of the sum of all 8 sinusoids above, whereas the bottom frame contains a harmonic complex with the fundamental and 2 nd component missing (sum of components $3-8$ ). Tones F1, F1-8, and $\mathrm{F} 3-8$ all have the same period $\mathrm{P}(10 \mathrm{~ms}$ in this example). Fundamental frequency $1 / \mathrm{P}=\mathrm{F} 1$ was the parameter changed along the frequency ordinate in Figs. 2, 4, 5, 7, 9, 10, and 11. It is identical with the sine-wave frequency for pure tones and the fundamental component of a complex regardless of the presence $(\mathrm{F} 1-8)$ or absence $(\mathrm{F} 3-8)$ of a sinusoid at that frequency. Amplitudes are normalized for clarity. 
off frequency of $20 \mathrm{kHz}$. Up to 15 sinusoidal components of individually specified frequency and amplitude could be digitally summed into a complex tone. The white noise, used for search stimuli and unit testing, was produced by a Coulbourne S81-02 noise generator. The signals were switched by a Coulbourne S84-01 rise/fall gate with linear 5-ms ramps. Sounds were presented to the animal within an electrically shielded, sound-treated booth from an overhead speaker (ADS 200 or ADS L520). The monkey's head was positioned on the speaker's axis, $\sim 1 \mathrm{~m}$ from the drivers.

The tones generated by the digital synthesizer were automatically calibrated by computcr. A 0.5 -in. Bruel and Kjaer condenser microphone was placed in the center of the space normally occupied by the animal's head. The amplitudes of 91 pure tones, spaced equally along a logarithmic scale from 80 to $18,000 \mathrm{~Hz}$, were measured by an HP 3582A spectrum analyzer and stored in a rable in computer memory to be used as a reference for the production of tones of known amplitude. Amplitudes are expressed in decibels sound pressure level (dB SPL) relative to $2 \times$ $10^{-5} \mathrm{~N} / \mathrm{m}^{2}$. Tone amplitudes at intermediate frequencies were interpolated from the table. No harmonic or intermodulation distortion was measurable for the range of amplitudes and frequencics used.

\section{Surgical procedures}

A stainless steel chamber was stereotactically implanted vertically over the auditory cortex under aseptic precautions and pentobarbital sodium anesthesia ( $35 \mathrm{mg} / \mathrm{kg}$ ip). A trephination with a $2 \mathrm{~cm}$ diam was made in the parietal bone with its center located $5.9 \mathrm{~mm}$ anterior to the stereotaxic ear bar zero and $20.5 \mathrm{~mm}$ lateral from the midline (coordinates adapted from Pfingst and O'Conner 1980), and stainless steel anchoring screws were placed around the chamber in the skull bone. The chamber was set in place with a stereotaxic positioning device and cemented to the skull with dental acrylic together with a stainless steel holding rod used later to immobilize the head during recording sessions. A threaded Teflon cap was screwed onto the chamber to seal it. The meninges were left intact. The animals were allowed at least $1 \mathrm{wk}$ to recover before the recording sessions were begun.

\section{Recording procedures}

Recordings were obtained in daily sessions of 1-2 $\mathrm{h}$ during weekdays. The animals were continuously observed by closedcircuit television. They commonly produced hand- and saccadic eye movements. When drowsiness was suspected they were alerted by briefly opening the door or by acoustic or somatosensory stimulation. They were thus usually alert. Epoxylite-coated tungsten microelectrodes $(0.8-2.0 \mathrm{M} \Omega$ impedance at $1 \mathrm{kHz})$ werc used to record extracellular action potentials from cortical neurons. The electrode tips were protected when penetrating the dura mater by a 22-gauge stainless steel guide tube. The electrode was attached to the microdrive so that it was recessed $1.2 \mathrm{~mm}$ within the guide tube when the microdrive was fully retracted.

The monkey's head was immobilized by bolting the stainless steel holding rod to a socket attached to the primate chair in which the monkey sat during recording. A Trent Wells X-Y positioner affixed to the chamber provided definition of electrodetrack coordinates within a $1.00 \times 1.00-\mathrm{cm}$ grid. The guide tube and electrode were inserted into parietal cortex above the superior temporal plane, and the electrode was advanced into auditory cortex with the microdrive.

The amplified spike signals from the microelectrode were fed into a window discriminator and to a digital storage oscilloscope. Each discriminated spike waveform was compared with a previously stored reference waveform to ensure absolute isolation of single neurons. Pulses from the discriminator were conducted to the computer and displayed as points in dot raster plots (e.g., Fig. 2). Each row of dots represents spike activity before, during, and after a 200-ms sound burst. Frequencies were presented in a pseudorandom order and sorted along the frequency axis by the computer. Data were acquired in 500-ms sweeps with the use of a binwidth of $2 \mathrm{~ms}$ with a 100 -ms delay until stimulus onset. Histograms could be taken with respect to either the time or frequency axis from the dot rasters.

Irregularly spaced $200-\mathrm{ms}$ noise pulses were usually used as search stimulus to find and isolate auditory units. Single units were tested with sets of pure and complex tones, as well as white noise, at several intensities. The pure-tone frequencies and complex-tone components were taken from the table of calibrated frequencies. The complex tones were usually composed of harmonic components $1-8$, component 1 being the fundamental $\left(\mathrm{F}_{0}\right)$. Missing fundamental stimuli contained up to component 11. Complex tones with frequencies $>18,000 \mathrm{~Hz}$ were presented with those components absent. To assess for inhibitory sidebands, best-frequency (BF) tones were presented at 20-30 dB above threshold together with a pure-tone series at the same or a different intensity.
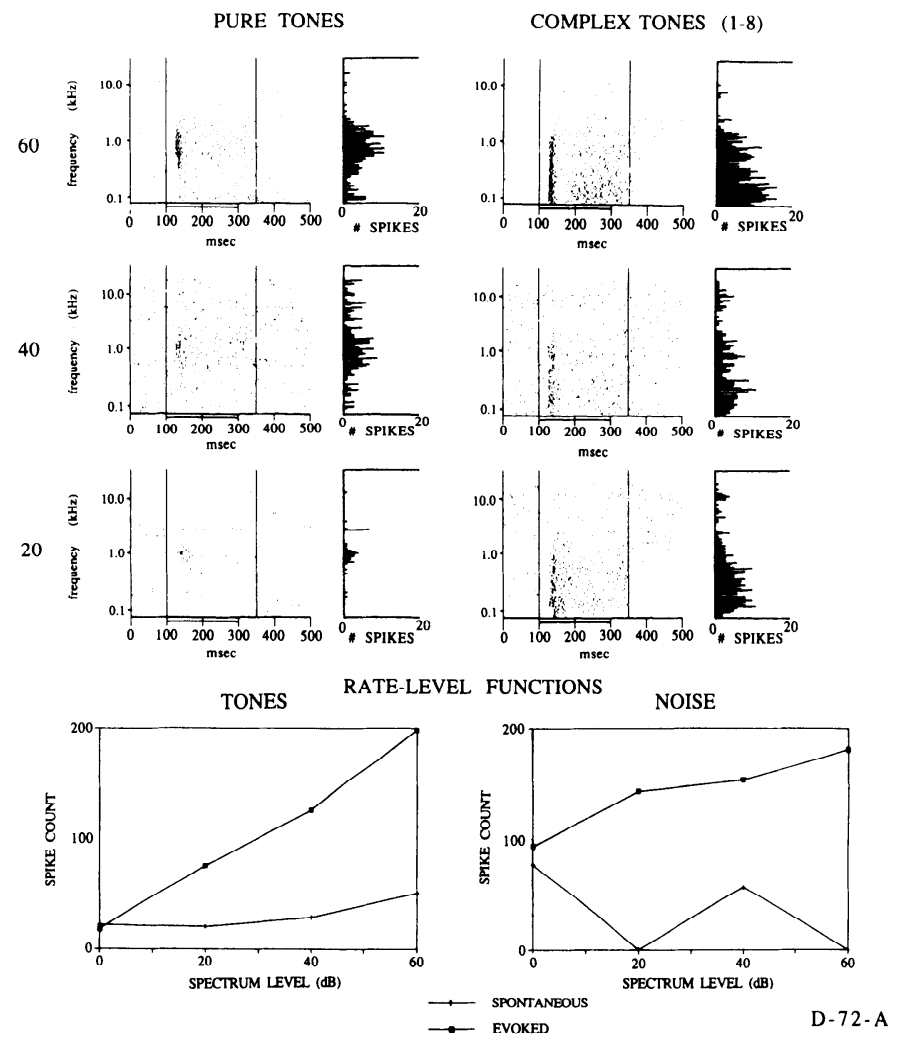

FIG. 2. Responses of a F neuron with an estimated CF of $1,000 \mathrm{~Hz}$. Left column of rasters contains responses to pure tones, and right column of rasters shows responses to complex tones (components 1-8, with 1 being the fundamental). Each dot in the rasters denotes an action potential. $Y$-axes represent fundamental-or pure-tone frequency-of the stimulus along a logarithmic scale in 91 equal steps from 84 to $18,000 \mathrm{~Hz}$. Frequencies are shown in $\mathrm{kHz}$. $X$-axes represent time measured in 2-ms bins. Bars indicate 200-ms-stimulus sound bursts. Frequency histograms (FH) to the right of each raster are computed by counting dots between the 2 vertical lines in rasters. FH $y$-axes are the same as in rasters. FH $x$-axes represent spike counts. Two bottom panels show rate-level functions for pure tones at $\mathrm{CF}$ and noise. $Y$-axes represent spike counts and $x$-axes stimulus amplitude in dB SPL. Evoked responses to tones or noise ( $\square$ ) were determined by counting spikes between 20 and $250 \mathrm{~ms}$ after onset of 40 repeated bursts. Spontaneous activity $(+)$ was estimated by counting spikes in the $100 \mathrm{~ms}$ before each stimulus. 
At the end of the series of electrode tracks in an animal, placed over a period of several months, two or three small electrolytic lesions ( $10 \mu \mathrm{A}$ cathodic current for $10 \mathrm{~s}$ through a recording microelectrode) were placed at selected recording sites. After a period of at least 3 days the animal was killed by transcardiac perfusion with warm saline under deep barbiturate anesthesia. The brain was fixed by subsequent perfusion with $10 \%$ buffered formalin and postfixed for 7 days by immersion in the same solution. The fixed brain was embedded in celloidin (M4) or frozen (M2 and M3) and cut into $30-\mu \mathrm{m}$ sections that were stained with cresyl violet or Thionine. The sections were then examined under the microscope to locate the electrolytic lesions, electrode tracks, and primary auditory koniocortex. The criteria and nomenclature of Pandya and his co-workers (Galaburda and Pandya 1983; Pandya and Sanides 1973) were adopted.

\section{RESULTS}

Responses to pure tones, harmonic complex tones, and noise at various intensities were obtained from 476 neurons isolated from 176 electrode tracks in the primary auditory cortex and adjacent cortical areas in three rhesus monkeys. The spectral selectivities displayed in all neuronal responses can be described as relatively simple filter functions. Responses are usually dominated by one excitatory response area combined with one or more inhibitory bands that are generally contiguous with the excitatory response area in a frequency/intensity coordinate system. A large response variety in both excitatory and inhibitory frequency bands suggested that neuronal filter functions varied continuously along several dimensions including the neuron's excitatory bandwidth, the response strength, and the frequency range and power of inhibition. (The term "inhibition" is used in this report to describe depression of spontaneous or evoked impulse rate without implying assumptions about the nature or location of possible responsible synaptic mechanisms.) Along this multidimensional continuum in spectral responsiveness of cortical neurons, it proved useful to distinguish five elementary response classes. These include 1 ) filter (F) neurons, 2) high-resolution filter (HRF) neurons, 3) $\mathrm{F}_{0}$ neurons, 4) wideband (WB) neurons, and 5) narrowband (NB) neurons.

It was possible to classify 251 neurons in this manner. The relative distribution of these classes is given in Table 1 along with the $\mathrm{BF}$ ranges for each class. The quasi filter (QF) neurons listed in Table 1 are very similar to $F$ neurons but share an important property of $F_{0}$ neurons to some extent. The neuron group listed under the "miscella-

TABI.E 1. Cortical neurons

\begin{tabular}{llrr}
\hline \hline \multicolumn{1}{c}{ Class } & CF Range & $n$ & Percent \\
\hline Filter (F) & $184-18,000$ & 52 & 21 \\
Quasi filter (QF) & $100-18,000$ & 79 & 32 \\
High resolution filter (HRF) & $330-11,450$ & 27 & 11 \\
Fundamental (Fo) & $170-2,800$ & 8 & 3 \\
Narrowband (NB) & $100-280$ & 7 & 3 \\
Wideband (WB) & $248-9,100$ & 9 & 4 \\
Miscellaneous & $100-18,000$ & 67 & 27 \\
Total & & 251 & 100 \\
\hline
\end{tabular}

$\mathrm{CF}$, characteristic frequency; $n$, number of neurons tested. neous" category is characterized by a combination of properties of two or more of the other classes.

\section{F neurons}

An example of a $\mathrm{F}$ neuron is presented in Fig. 2. Each dot in the raster displays represents one action potential. In the left column of rasters, responses to pure tones are shown at three intensities (20,40, and $60 \mathrm{~dB}$ SPL). It can be seen that both the number of spikes per stimulation frequency as well as the frequency range producing a response increases with intensity. The increasing response bandwidth is better appreciated when all spikes in the time window, indicated by the vertical bars in the rasters, are summed to yield frequency histograms (FH) shown to the right of each raster. From these FHs, a BF can be derived, BF being the frequency with the greatest response-rate probability. As evident in the pure-tone FHs, the BF was not as well defined at high intensities as it was close to threshold. Thresholds were not precisely determined in these experiments, although the lowest intensity plots were obtained within 10 or $20 \mathrm{~dB}$ of threshold (lower intensity stimuli yielding no visible response). BF at the lowest response intensity was accepted as an estimate for the characteristic frequency (CF) of the neuron, and corresponding $\mathrm{CF}$ values are the bases for neuronal frequency specificities in this report as given, for example, in Table 1 or Figs. 14 and 15 . F neurons often had monotonic spike rate/intensity functions for CF stimuli over the available intensity range. As exemplified in the diagram below the pure-tone rasters (Fig. 2), the complete dynamic range was not usually measured because of the severe limitations in recording time (maximum $2 \mathrm{~h}$ ) for each neuron in these alert primate preparations.

The right column of rasters in Fig. 2 shows the responses of this neuron to harmonic complexes consisting of the lowest eight consecutive components at the same intensity per component used for the pure tones $(20,40$, and $60 \mathrm{~dB}$ SPL). Raster plot and FH ordinates represent the fundamental frequency (component 1 or $F_{0}$ ). It can be seen that the frequency range now extends from the upper pure-tone response limit $(\mathrm{Fu})$ to frequencies much lower than the lower frequency limit (F1) for pure tones. This extension of the frequency-response range to low frequencies is readily understood on the basis of the frequency composition of the stimulus complexes that contained components up to three octaves above the fundamental frequency. As illustrated in Fig. 3, the lowest response frequency should correspond to three octaves below the pure-tone F1 (Fig. 3B), whereas the high frequency limit of the complex-tone response area should coincide with the pure-tone Fu (Fig. $3 C$ ). The heavy vertical lines to the left and right in Fig. 3 summarize the frequency-response ranges for pure tones and complex tones, respectively. Such a response pattern would be expected of a simple band-pass filter (hence the name "filter neurons"). A criterion for the classification of F neurons was that stimulus components present between Fu and F1 should generally yield a response, that is, eight component complexes had to extend the response area at least two, but not more than threc, octaves below F1.

Presence of more than one component of the complex in 
the pure-tone response area should increase the response strength as long as the unit's response firing rate is not saturated. This trend is evident in Fig. 2 when the FHs for pure and complex tones are compared. Similarly, relatively stronger responses should result from wideband noise stimuli, which is suggested in the rate/intensity diagram below the right raster column in Fig. 2. It is, however, impossible to arrive at a systematic quantitative evaluation of such relationships because the background firing rate of neurons varied widely during all recording sessions, and a simple response magnitude estimate (difference between evoked and spontaneous rate) is probably not valid in the alert cortex. F neurons are the most commonly observed neuron class. Because their estimated CFs ranged from 184 to $18,000 \mathrm{~Hz}$, they appear to represent the entire audible frequency range. There was no clear evidence for inhibitory sidebands in the dot rasters and FHs, and when an attempt was made to suppress a BF response with a second puretone stimulus at systematically altered frequencics, there was also no indication for inhibition along the frequency dimension in $\mathrm{F}$ neurons. In summary, units were classified as $F$ neurons if they responded well to pure tones and noise and displayed no convincing evidence for sideband inhibition. The fundamentals of the complex-tone response areas covered single-frequency ranges extending from pure-tone $\mathrm{Fu}$ to at least two octaves (but not exceeding 3 octaves) below F1. If the lowest fundamental for complex-tone responses extended to the lowest frequency tested $(84 \mathrm{~Hz})$ but less than two octaves below F1, it was also counted as $F$ neuron provided the other criteria were met.

A majority of cells (32\%, Table 1, QF neurons) exhibited response characteristics that were similar in all respects to $F$ neurons except that the extension of the response range for complex tones to frequencies below the pure-tone F1 was less than two octaves. Since the available data on these cells do not allow to define relevant inhibitory or suppressive mechanisms, they are listed in Table 1 as a separate class of

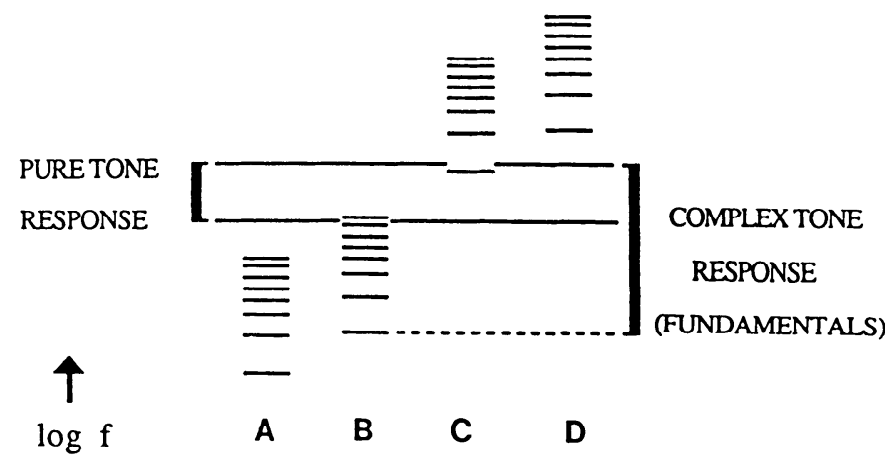

FIG. 3. Prediction of complex-tone responses from a F neuron's puretone response area. Harmonic complexes contain components 1-8. Frequency is represented along a vertical logarithmic scale. Unit's upper and lower pure-tone response limits, Fu and F1, are shown as long horizontal lines. Pure-tone response area is illustrated by a thick vertical bar on the left. Four examples of complex tones are shown, represented by sets of horizontal lines, one line for each component of the complex. Bottom line in cach set represents the fundamental of the complex. In complex $A$ all components are below $\mathrm{F} 1$; in $\mathrm{B}$ the highest component is just above $\mathrm{F} 1$; in $\mathrm{C}$ the lowest component is just below $\mathrm{Fu}$, and in $\mathrm{D}$ all complex-tone components are above Fu. Vertical bar on the right shows the range of fundamental frequencies for complexes with components in the pure-tone response area, which extends from Fu to 3 octaves below F1.
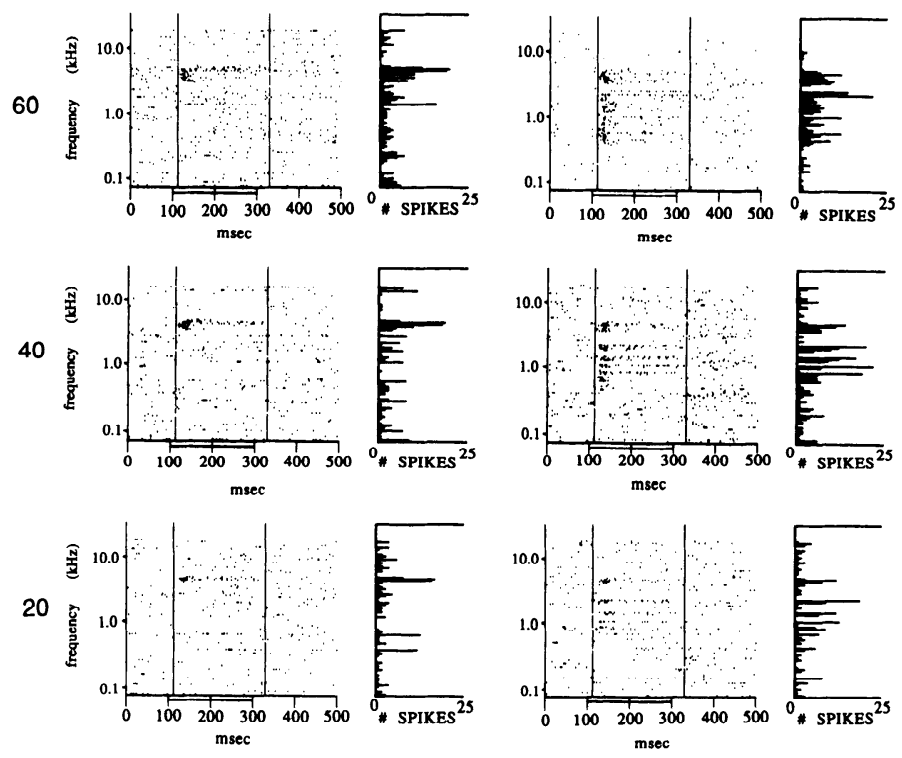

J-2-C

FIG. 4. Responses of a HRF neuron (unit J-2-C) with an estimated CF of $4,200 \mathrm{~Hz}$. Left column of rasters and FHs contains responses to pure tones, and the right column shows responses to complex tones with components 1-8. Axes of rasters and histograms are as described in Fig. 2. Numbers to the left of each row designate the SPL of the stimulus in $\mathrm{dB}$ SPL.

QF cells. This name is meant to stress the possibility that these cells may be a simple variation of $F$ neurons.

\section{HRF neurons}

If the pure-tone response range in Fig. 3 (the heavy line to the left) would be narrower than the separation between frequency components of the complex tones, single components would give rise to individual response ranges as the fundamental frequencies would be stepped from low to high. This would result in a series of discrete complex-tone response areas, that is, the heavy bar to the right would have to be drawn fragmented. Neurons with such a series of distinct complex-tone response areas were classified as

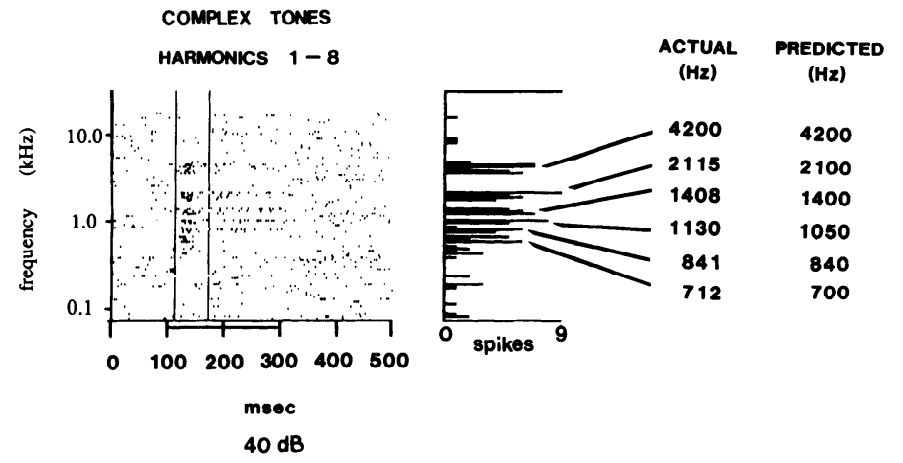

FIG. 5. Response bands to complex tones when fundamental frequencies are at subharmonics of the pure-tone BF for HRF neuron of Fig. 4. Left column of numbers shows frequencies measured from $\mathrm{FH}$ peaks, and the right column shows predicted peaks based on subharmonics of 4,200 $\mathrm{Hz}$ (i.e., 4,200/1, 4,200/2, 4,200/3, . . , 4,200/6). 


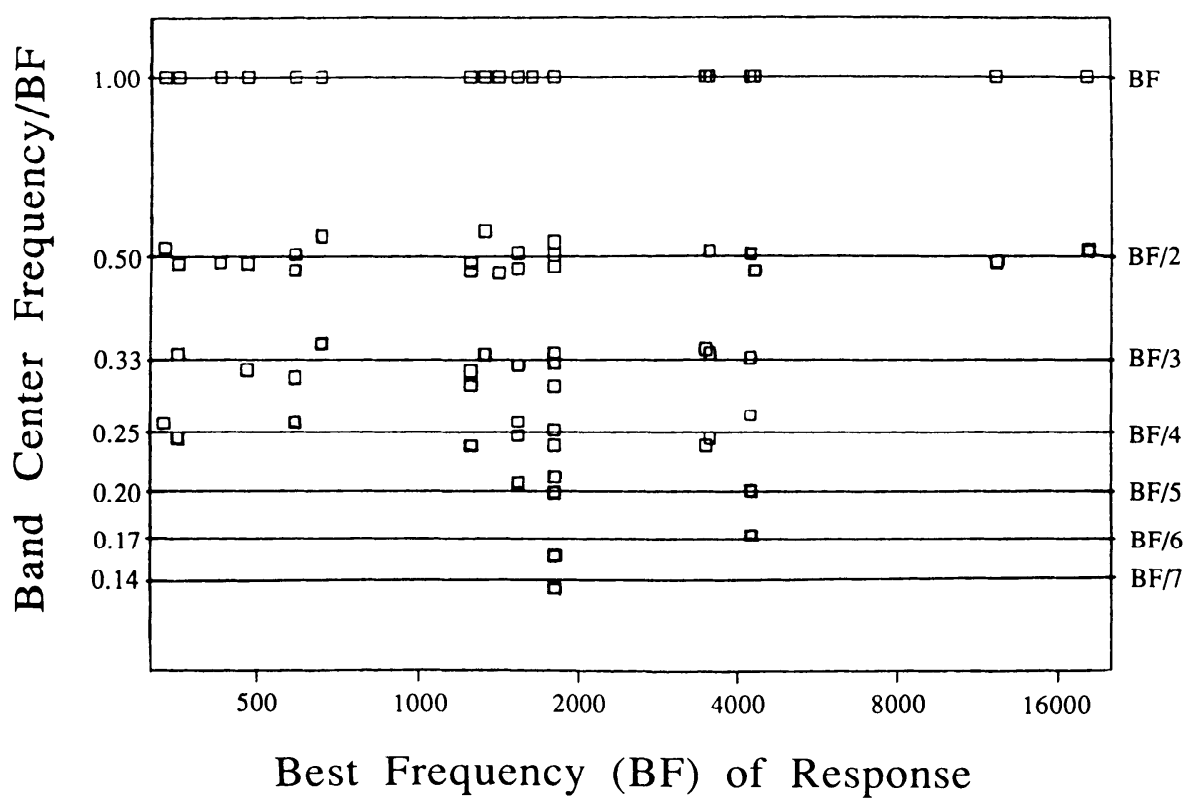

FIG. 6. Peak frequencies in complex-tone FHs of HRF neurons compared with subharmonics of BFs. BFs are represented along the horizontal axis. Vertical axis shows frequencies of peaks normalized to $\mathrm{BF}$ and plotted on a logarithmic scale. Horizontal lines show locations of BF subharmonics.

HRF neurons, because they could be modeled by the assumption of simple narrow band-pass-filter characteristics. An example is shown in Fig. 4. The narrow frequency-response areas resulting from pure-tone stimuli differ strikingly from the response ranges of $F$ neurons. There is only a slight widening of the bandwidth with increasing stimulus intensity. The individual response bands displayed in the rasters for complex tones (right) are a direct consequence of the narrow pure-tone response band resulting in individual peaks in the FHs. To clarify the complex-tone response pattern further, it is useful to consider a hypothetical HRF neuron responding only to pure tones at the CF. As the fundamental frequency of an eight-component harmonic complex is increased, the first component to enter the receptive field will be the eighth component. The neural response, plotted at the fundamental frequency, will appear on the raster display and $\mathrm{FH}$ at one-eighth of the CF. As the seventh component enters, a response will appear at a fundamental that is one-seventh of the CF, and so forth. The resulting plot will have response bands at the first through the eighth subharmonics of the CF. Figure 5 compares the subharmonics of $4,200 \mathrm{~Hz}$ (the CF of the HRF neuron in Fig. 4) with the center frequencies of each band in the complex-tone response at $40 \mathrm{~dB}$. The close correspondence of both lists suggests that a simple narrowband-pass-filter function can indeed account for the complex-tone response pattern in this HRF neuron. In further support of

TABLE 2. HRF neurons

\begin{tabular}{ccc}
\hline $\begin{array}{c}\text { Maximum Components } \\
\text { Resolved }\end{array}$ & Number of Units & Dynamic Range \\
\hline 2 & 4 & $10-30$ \\
3 & 12 & $10-30$ \\
4 & 5 & $10-50$ \\
5 & 2 & $10-35$ \\
6 & 1 & 40 \\
7 & 1 & 30 \\
\hline
\end{tabular}

Dynamic ranges given in decibels. HRF, high-resolution filter. this hypothesis, Fig. 6 shows the correlation between observed and predicted frequency values for the bands in the complex-tone responses of all HRF neurons. The neuronal BFs are represented along the horizontal axis. The vertical axis shows the frequencies of the FH peaks normalized to the BF; the horizontal lines show the subharmonics for the BFs. The measured values appear to be reasonably well clustered about the lines. A $\chi^{2}$ test verifies the closeness-offit of the measured values to the predicted subharmonics of BF to a $P=0.05$ level. It appears that this population of cortical neurons can respond discretely to components of harmonic complex tones.

As a rule the complex-tone response bands of HRF neurons were most distinct for $F_{0}$ frequencies close to pure-tone BF because the frequency separation of the lowest components is greatest along the logarithmic frequency scale. Bands resulting from lower fundamentals (lower subharmonics) are correspondingly less well defined. Because the response bandwidth for pure tones varied, the number of response bands would differ as well. These numbers are listed for HRF neurons in Table 2 together with the stimulus-intensity ranges over which such neuronal resolving power could be observed. In Table 3, it is shown how estimated CFs of HRF neurons are distributed over the frequency range subdivided into seven octaves. The apparent predominance of midfrequency $\mathrm{CF}$ values does

TABLE 3. Distribution of CFs of HRF neurons in 7 octaves

\begin{tabular}{cc}
\hline Frequency Range & Resolver Neurons with $C F$ \\
\hline $125-250$ & 0 \\
$250-500$ & 5 \\
$500-1,000$ & 3 \\
$1,000-2,000$ & 12 \\
$2,000-4,000$ & 3 \\
$4,000-8,000$ & 2 \\
$8,000-16,000$ & 2 \\
\hline
\end{tabular}

Frequency range given in $\mathrm{Hz} . \mathrm{CF}$, characteristic frequency; HRF, highresolution filter. 
not imply that midfrequency CFs are more likely for HRF neurons because the same $C F$ values predominated over the entire neuron sample (cf. Fig. 13 to Fig. 15).

It is evident in Fig. 4 that there was a tendency for spike suppression in frequency areas immediately adjacent to excitatory response bands. Corresponding sideband inhibition was observed in several HRF neurons with two-tone testing and is probably responsible to some extent for the narrow frequency range as well as the very limited growths of the response bandwidth with intensity that is characteristic for HRF neurons. All of these cells responded well to noise stimuli, although some had nonmonotonic rate-level functions with white noise, pointing again to inhibitory response areas.

\section{$F_{0}$ neurons}

An example of this neuron class is shown in Fig. 7, $A$ and $B$. The main criterion for $\mathrm{F}_{0}$ neurons is that frequency tuning for pure tones is similar to that for fundamental

\section{A}

PURE TONES
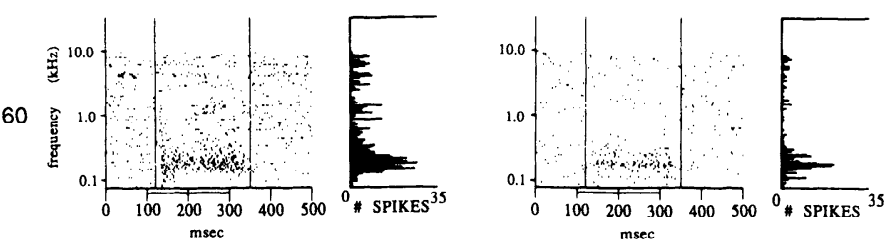

COMPLEX TONES $1-8$
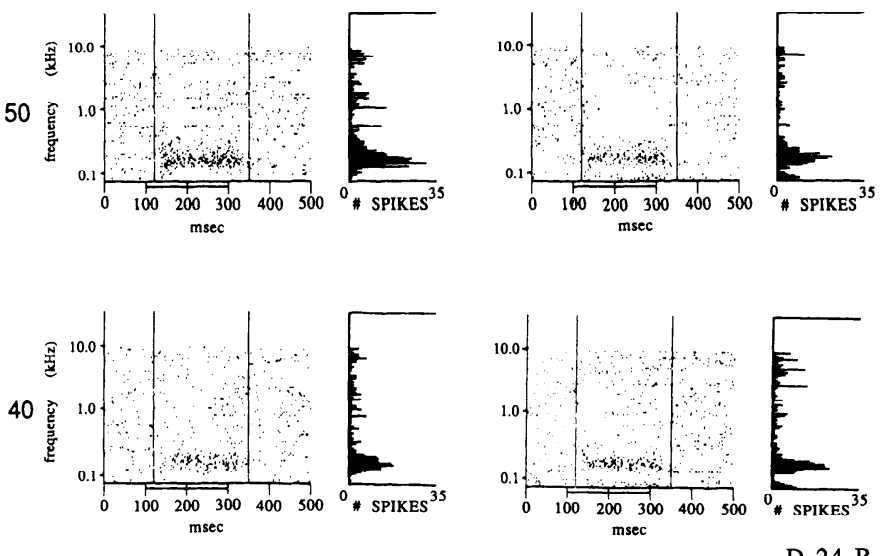

D-24-B

RATE-LEVEL FUNCTIONS

TONES
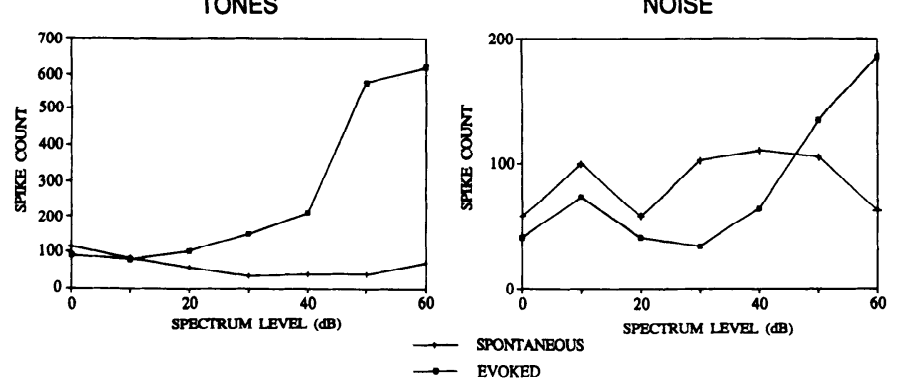

frequencies of complex tones. It can be seen in the puretone raster plots and FHs that the response bandwidth was relatively constant with respect to stimulus intensity. Response amplitudes to pure tones saturated within some $20-40 \mathrm{~dB}$ of threshold, and there was a suppression of spike activity at frequencies below the pure-tone excitatory band. This low-frequency inhibitory sideband seems to be the cause for tuning to the fundamental frequency that is shown in the complex-tone rasters and FHs of Fig. $7 \mathrm{~A}$. Upper harmonic components falling into the inhibitory sideband would simply suppress spike activity so that only the fundamental frequency could activate the neuron. The low-frequency inhibition becomes stronger with increasing intensities. This is shown in the two-tone rasters and FHs of Fig. $7 \mathrm{~B}$ where a $\mathrm{CF}$ tone at $40 \mathrm{~dB}$ was presented together with second tones of systematically changing frequencies. The inhibitory sideband is clearly evident by the suppression of the $\mathrm{CF}$ tone response with $60-\mathrm{dB}$ suppressor tones. In the $50-\mathrm{dB}$, two-tone plot it can be seen that the inhibi-

\section{B COMPLEX TONES 4-11}
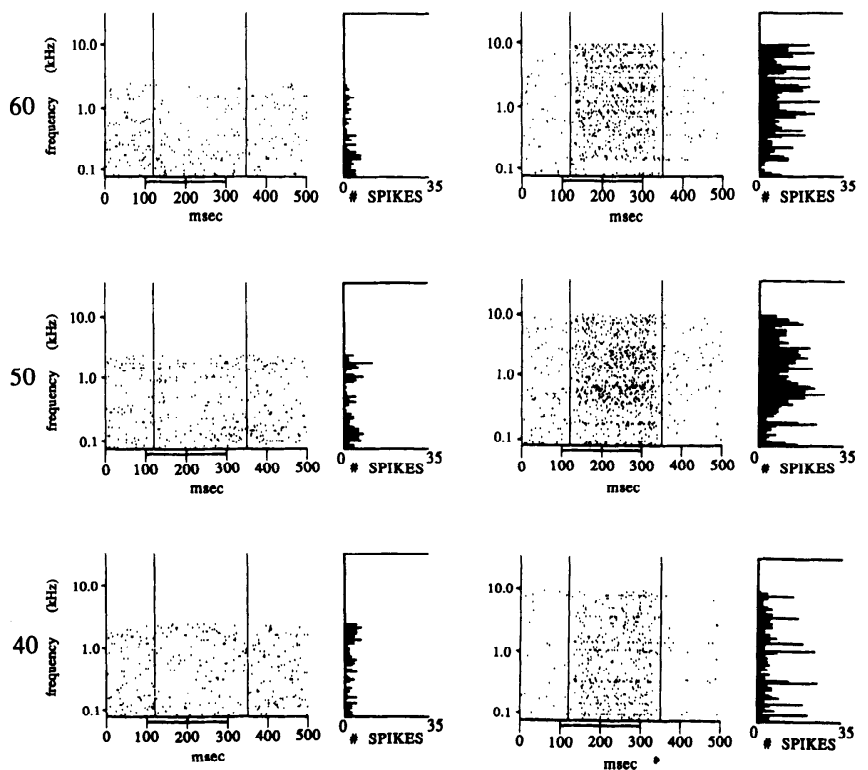

msec

FIG. 7. $A$ : responses of a $\mathrm{F}_{0}$ neuron with a $\mathrm{CF}$ of $173 \mathrm{~Hz}$. Numbers to the left of each row of rasters designate spectrum levels in dB SPL. Left column shows responses to pure tones. Responses to complex tones containing components $1-8$ are in the right column. $B$ : left column shows responses to a series of complex tones missing their fundamentals (components 4-11); right column shows series of responses to 2-tone stimulation. Fixed tone had a frequency of $173 \mathrm{~Hz}(\mathrm{CF})$ and an amplitude of $40 \mathrm{~dB}$. Numbers to the left of the rasters show the intensity of the 2 nd simultaneously present tone. Bottom panels show rate-level functions to $173-\mathrm{Hz}$ pure tones (left) and white noise (right). 


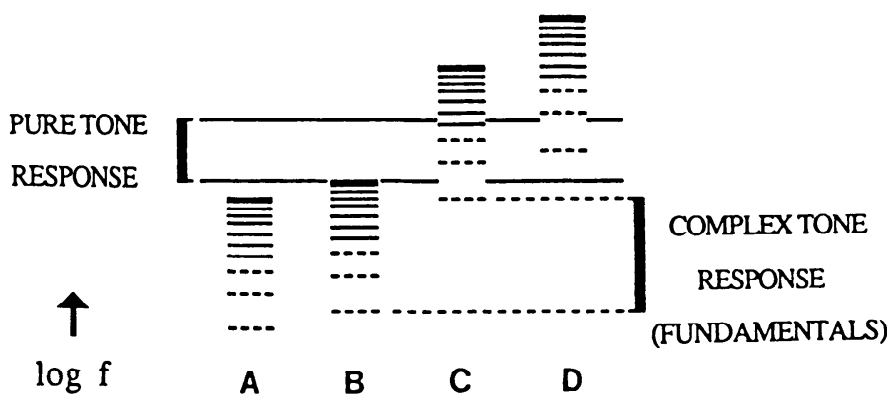

FIG. 8. Responses to complex tones missing lowest 3 components (including fundamentals). Explanations as in Fig. 3, except that missing components are shown as dashed lines. Heavy bar to the right shows the complex-tone response area in $\mathrm{F}$ neurons that is suppressed in $\mathrm{F}_{0}$ neurons.

tory sideband extends into the CF area so that only responses very close to the CF remain.

It may be tempting to consider neurons equally well tuned to complex fundamentals and pure tones as pitch encoders, because they respond similarly to physically different tones with the same periodicities. The response pattern of the neuron of Fig. 7, $A$ and $B$, cannot reflect a specific pitch, however, because there is no response to missing fundamentals. Examples are shown for complex tones consisting of components $4-11$ in Fig. $7 B$. Figure 8 explains why complexes missing their fundamentals and lower components cannot cause strong responses in $F_{0}$ neurons when the fundamental frequency is equal to the pure-tone BF. The physically presented stimulus components are shown as solid lines and the missing three lowest components, including the fundamental, as dashed lines. Fundamental frequencies that might lead to an excitation would fall within the frequency range indicated by the

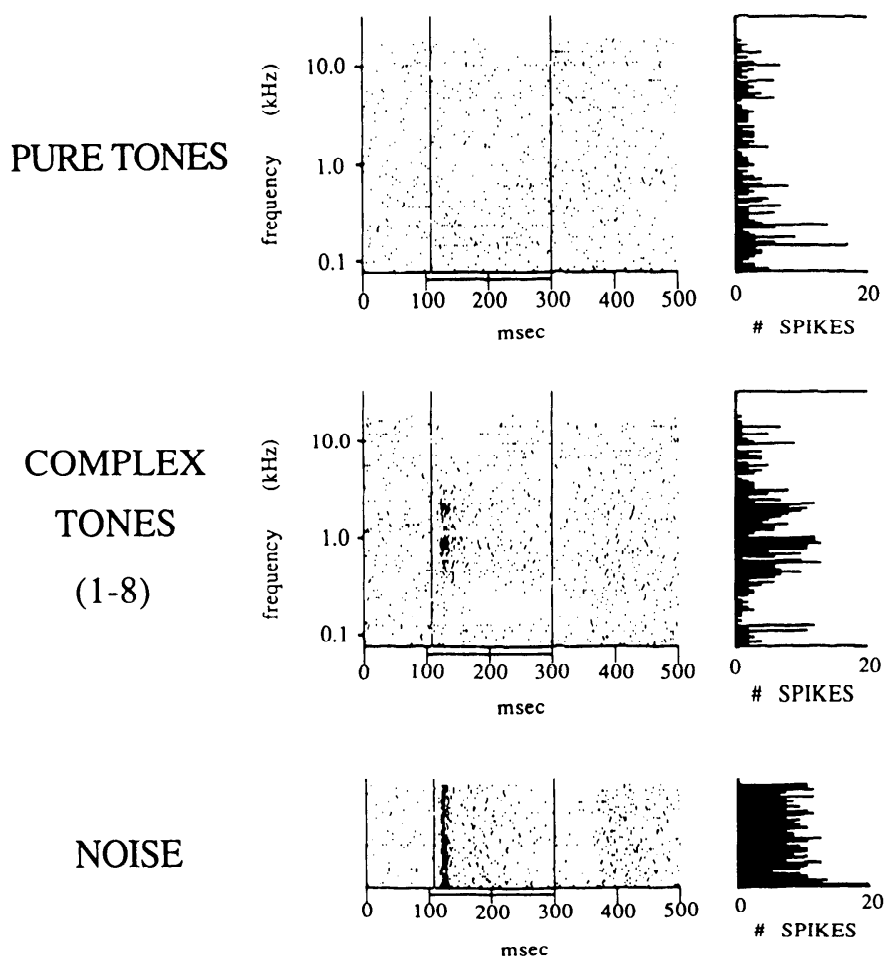

FIG. 9. Responses of a WB neuron to pure tones, complex tones, and noise at $50 \mathrm{~dB}$ SPL.

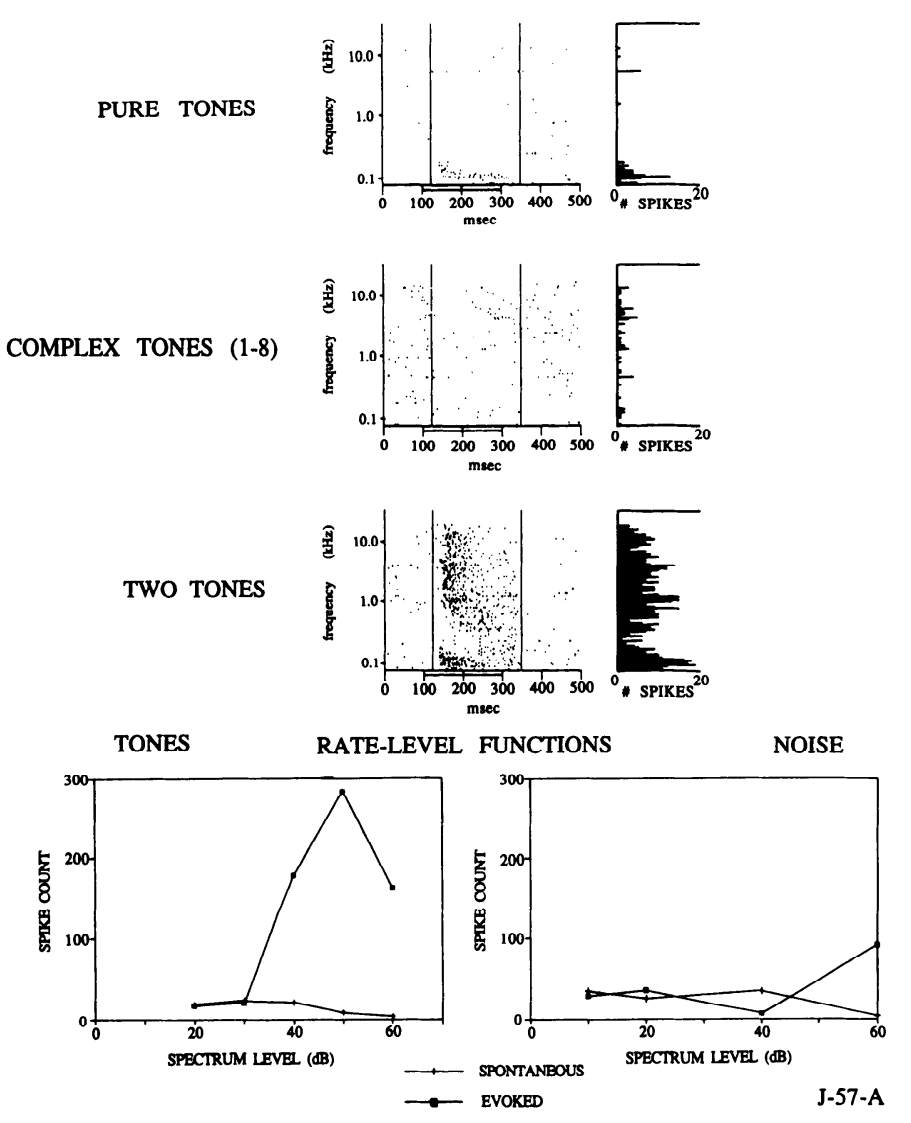

FIG. 10. Responses of a NB neuron with a CF of $121 \mathrm{~Hz}$. Responses to pure and complex tones (1-8) at amplitudes of $40 \mathrm{~dB}$ SPL are shown in the top 2 rasters. Bottom raster shows inhibition of the evoked response to a $40-\mathrm{dB}$ tone at $121 \mathrm{~Hz}$ by a $2 \mathrm{nd}$ tone series at $45 \mathrm{~dB}$. Bottom 2 panels contain rate-level functions for $121-\mathrm{Hz}$ purc tones and noise.

heavy bar to the right if response selectivity were entirely determined by the pure-tone excitatory response area (as in $F$ neurons). Because there is an additional low-frequency inhibitory sideband in $F_{0}$ neurons, no response at all is seen. An additional reason for the lack of responses to missing fundamental complexes in the unit of Fig. 7, $A$ and $B$, is that the corresponding fundamental frequencies would extend below the plotted frequency range.

Overall, $F_{0}$ neurons responded well to a wide variety of sound stimuli, including pure and complex tones as well as noise. As exemplified in the panels at the bottom of Fig. $7 B$, intensity/rate functions were generally monotonic.

\section{WB neurons}

It was demonstrated above that $\mathrm{F}$ neurons can produce a stronger response if the number of frequency components falling into the pure-tone response area is increased, even if the amplitude per component is kept constant. The reason is, of course, that the total sound energy of multicomponent or wideband stimuli is greater than that of pure tones at the same spectrum level. An eight-component complex tone has 8 times greater total energy than a pure tone at the same level, corresponding to an increase of $9 \mathrm{~dB}(3 \mathrm{~dB}$ per doubling of energy). A cell was classified as a wideband neuron if it responded better to an eight-component complex-tone series than to a pure tone having a 10-dB-greater spectrum level. An example is shown in Fig. 9. Spectrum 
level for all three plots was $50 \mathrm{~dB}$ SPL, an intensity that would always yield pure-tone responses in $\mathrm{F}$ neurons with midrange CFs. No such response can be observed in the pure-tone raster and $\mathrm{FH}$ for this cell. There is, however, a strong response to complex tones as well as to noise. The peak amplitude in the $\mathrm{FH}$ of the complex-tone series is approximately identical with the amplitude for the noise dot raster that was, of course, obtained by simply repeating identical noise stimuli 40 times. The histogram to the right merely indicates amplitude variability for the same stimulus. The eight-component complex can thus have the same excitatory effect as wideband noise. This suggests that inhibitory interactions cannot be strong, a conclusion that generally applies to WB neurons.

\section{$N B$ neurons}

A typical NB neuron is shown in Fig. 10. A very narrow range of pure tones around the $\mathrm{CF}$ of $121 \mathrm{~Hz}$ excites this cell, whereas no response is seen during stimulation with either complex tones or wideband noise at the same spectrum level ( $40 \mathrm{~dB}$ SPL). The two-tone test in the bottom dot raster and $\mathrm{FH}$ shows a powerful inhibitory sideband for frequencies above the pure-tone response area, whereas inhibition for frequencies below $F 1$ is less convincing. The inhibition seems to be predominant during the first onehalf of the response time. The inhibitory sideband explains the elimination of the response to complex tones because stimulation of the inhibitory band with upper components would abolish excitation by the fundamental and other low harmonics. The influence of the inhibitory sideband is also

\section{PURE TONES}
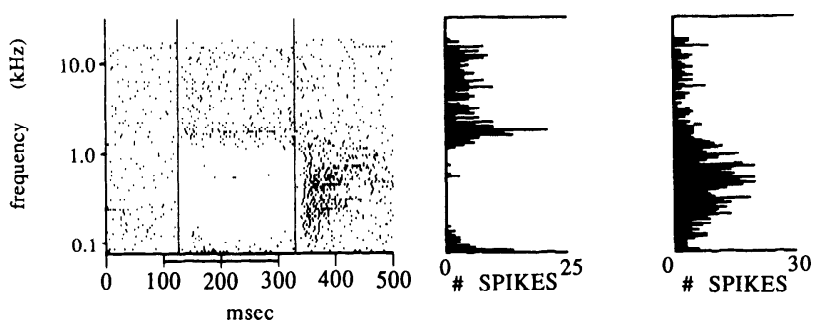

COMPLEX TONES 1-8
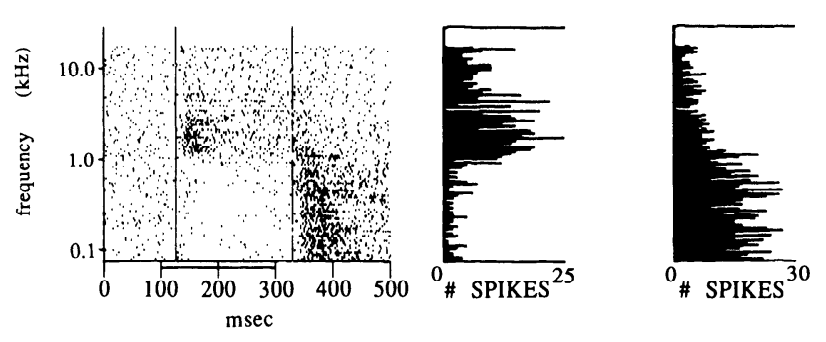

G-19-A

FIG. 11. Unclassified neuron responding like a $F_{0}$ cell during the stimulus, whereas the postinhibitory rebound (off response) is similar to an $F$ response. CF: $1,250 \mathrm{~Hz}$ for the response during the stimulus. Top, responses to pure tones; bottom, to complex tones (components $1-8$ ) at 50 dB SPL. Left histograms were computed over the time window indicated by cursors in rasters; right histograms were computed for the off response.
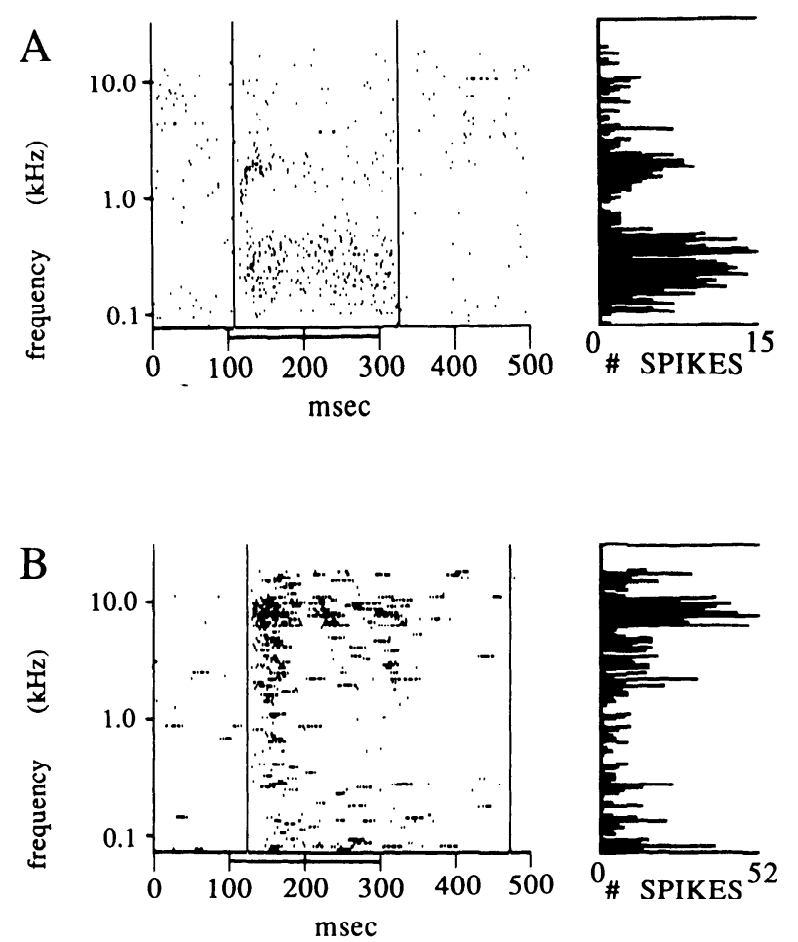

FIG. 12. $A$ : neuron with 2 excitatory response bandwidths. $B$ : neuron with a narrow response bandwidth throughout the stimulus duration and wide bandwidth for the on response.

expressed in the nonmonotonic rate-level curve for pure tones. There was very little response to noise as the noise rate-level function shows. All NB neurons observed had low CFs (maximum $280 \mathrm{~Hz}$ ). Because of the small sample size, it remains uncertain if this response pattern represents a low-frequency specialization. The principle distinguishing criterion between NB and HRF neurons is that the former do not respond well to wideband stimulation whercas the latter do.

\section{Miscellaneous response types}

For a relatively large proportion of cells $(27 \%)$ a decision about class membership could not be readily made, usually

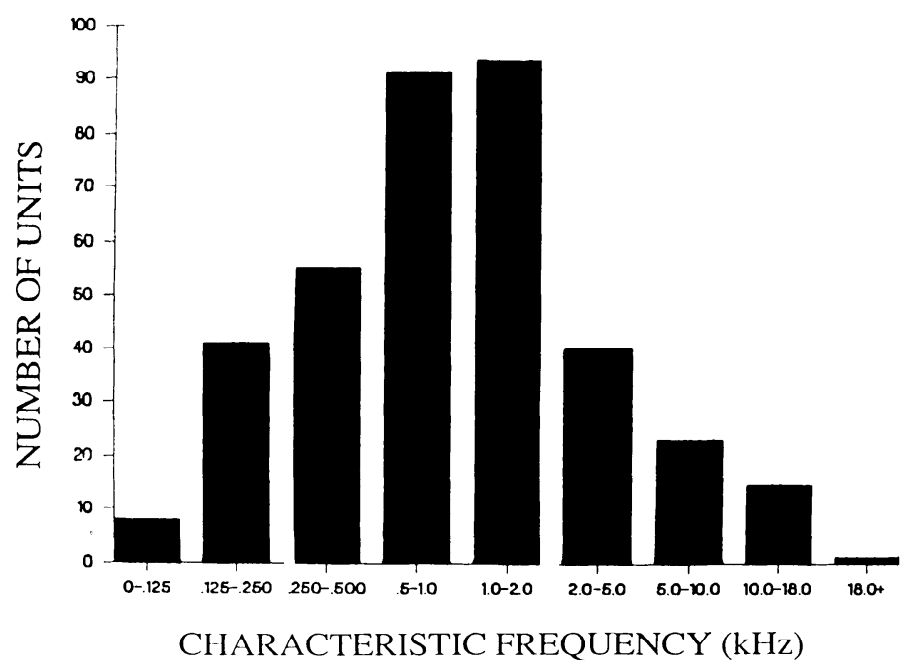

FIG. 13. Distribution of characteristic frequencies for 367 neurons. 
because their response patterns had attributes of two or more of the above classes. One example is shown in Fig. 11. Responses to pure and complex tones are compared at one spectrum level of $40 \mathrm{~dB}$ SPL. The response during the stimulus resembles that of a $F_{0}$ neuron with the characteristic low-frequency inhibitory sideband. The rebound activation after the inhibition ("off" response), on the other hand, follows the F-neuron pattern. It may appear justified to classify such neurons with contrasting responses during and after the stimulus according to the response during the stimulus, because sound coding necessary for perception is certainly complete before the $200-\mathrm{ms}$ sound stimulus is over. We did, however, not do this because we do not know the functional consequence of the off response.

There were also neurons with two excitatory response areas, an example being shown in Fig. $12 \mathrm{~A}$. Such neurons may perhaps be considered to produce the inverse response patterns of NB or HRF cells, as would be expected of inhibitory interneurons providing sideband inhibition.

Figure $12 B$ shows another neuron that was not classified

A

ANTERIOR

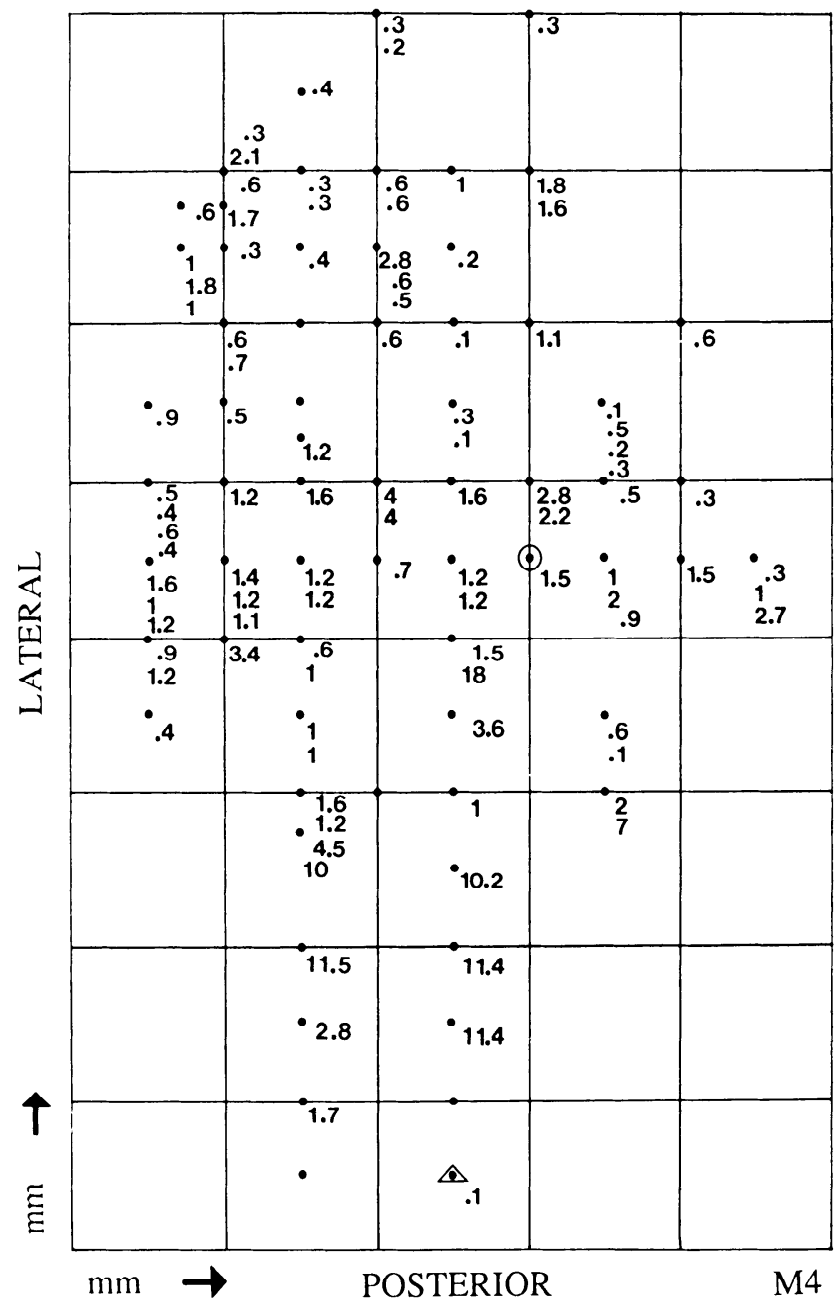

because filter characteristics of the onset response and the response during the rest of the stimulus period ("through" response) differed widely. The through response behaved like a regular F neuron. The wideband "on" response is probably not simply fed forward from cochlear afferents with a strong on response in the tail section of a correspondingly high-frequency tuning-curve fiber, because the cortical on response was also present at low intensities. More limited widening of onset bandwidths was also observed in neurons that were easier to classify (see, for example, the HRF neuron of Fig. 4 and the $F_{0}$ neuron of Fig. 7).

\section{Characteristic frequencies}

The distribution of estimated CFs of recorded neurons of all classes is shown in Fig. 13. The predominance of the midrange octaves may appear surprising in view of the fact that the monkey's auditory range extends to more than 45 $\mathrm{kHz}$ (Stebbins et al. 1966). A certain bias toward frequencies yielding the lowest thresholds in the ear may have been

B

ANTERIOR

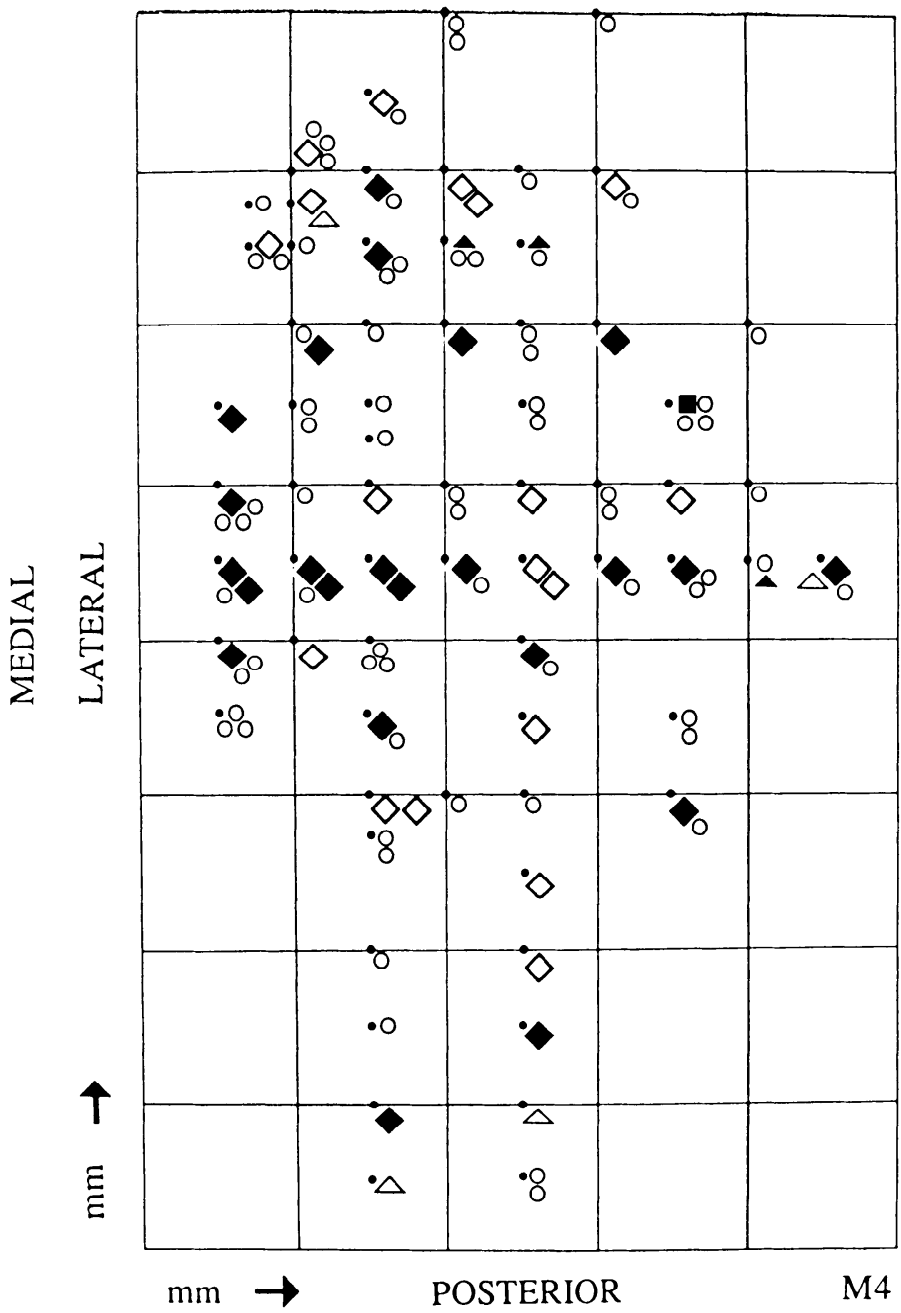

FIG. 14. A: locations of recording tracks ( $\bullet$ ) in auditory cortex of monkey $M 3$ projected onto the horizontal plane of the $\mathrm{x}-\mathrm{y}$ positioner on the recording chamber. Most tracks were in primary koniocortex. Numbers indicate estimated CFs for isolated neurons. $B$ : neuron classes in same tracks. Filled diamonds: $F$; open diamonds: HRF; filled triangles: $F_{0}$; open triangles: WB; filled squares: NB; and circles: unclassified neurons. 
introduced because we usually kept our stimulation intensity within 60-70 dB SPL to avoid distortion problems. More likely however, is, a relative over-representation of the midrange octaves, which appear to occupy a disproportionately large cortical territory (cf. Figs. 6, 8, 9, and 12 of Merzenich and Brugge 1973). CF ranges for the main neuron classes are listed in Table 1.

Intermodulation distortion products generated in the ear by complex-tone stimulation did not appear to contribute significantly to our data. Twenty-three cortical neurons were tested with complexes missing their fundamental, their CFs ranging from $170-3,700 \mathrm{~Hz}$, and amplitudes being varied between 10 and $60 \mathrm{~dB}$ SPL. Both $F$ and $F_{0}$ neurons were included in this sample. There was no evidence of responses at the frequency of the missing fundamental that could be produced by difference tones (F2-F1), cubic difference tones $(2 \mathrm{~F} 1-\mathrm{F} 2$, which are prominent in the cochlea, Evans 1975) or other intermodulation products. This is probably due to the intensity limitations for our stimuli, because difference or cubic-difference tones are heard by humans if component amplitudes are above 51-60 dB SPL (Plomp 1965, Smoorenburg 1972).

\section{Distribution of response characteristics over the cortical surface}

A topographic map of neuronal firing characteristics cannot be assembled from recordings obtained over several

A

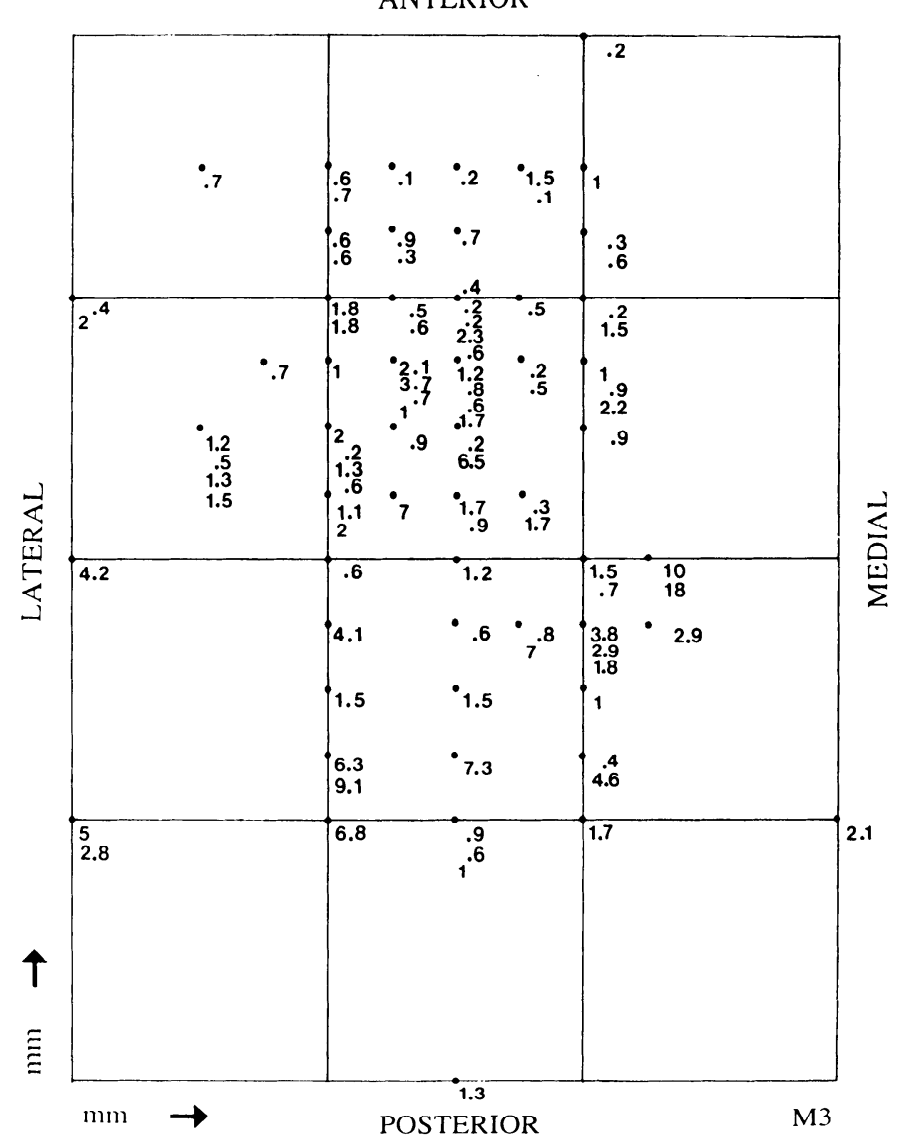

months in the alert monkey. Reasons for this are that relative positions of brain structures with respect to electrode target positions may have varied from time-to-time, and small pathological events associated with electrode penetration may have occurred. We, therefore, do not present systematic cortical maps for CFs and neuron classes but simply grid positions of recording tracks derived from the $X-Y$ positioner placed on the chamber during recording sessions for two monkeys. In these two monkey brains several electrolytic lesions derived from recording electrodes were found in koniocortex (kam and kalt) indicating that a large number of recordings must have been derived from primary auditory cortex (AI). The distribution of CFs across the $\mathrm{X}-\mathrm{Y}$ positioner grids shown in Figs. $14 A$ and $15 A$ support this notion. The lesion shown in Fig. $16 \mathrm{~A}$ corresponds to the track marked with a circle in Fig. 14A. From the accompanying illustrations of response-class distributions, it may be concluded that $F$ and HRF neurons dominate the populations in AI. This conclusion is further emphasized by the fact that the majority of unclassified neurons (shown as circles) consists of QF neurons. It is less certain whether the other neuron classes predominate in cortical areas adjacent to AI. In one monkey (M2) all electrode penetrations passed into the superior temporal plane posterior to the AI koniocortex. A lesion caused in this area in $M 4$ (Fig. 16B) was caused by the penetration identified with a triangle in Fig. 14A. Although all response classes

B ANTERIOR

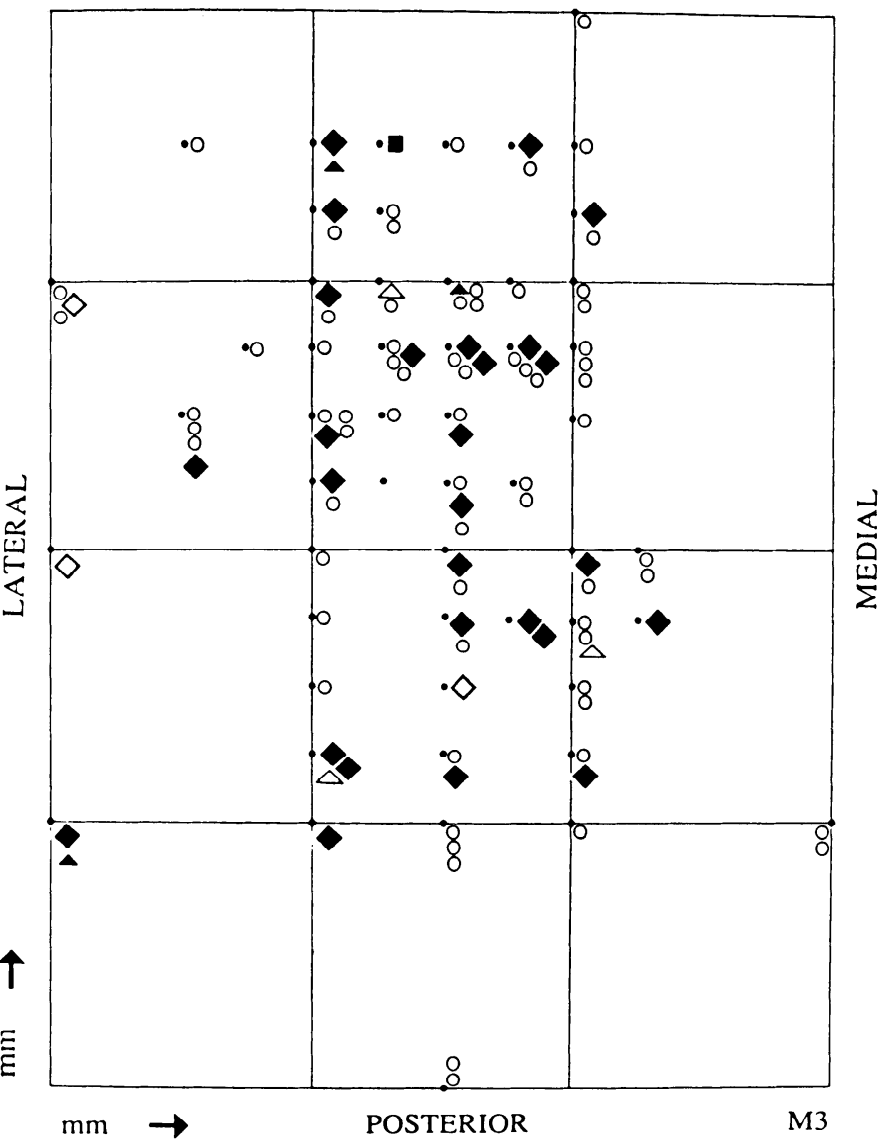

FIG. 15. A: locations of electrode tracks and estimated CF in auditory cortex of monkey M4. B: neuron classes in same tracks. Explanations and symbols as in Fig. 14. 

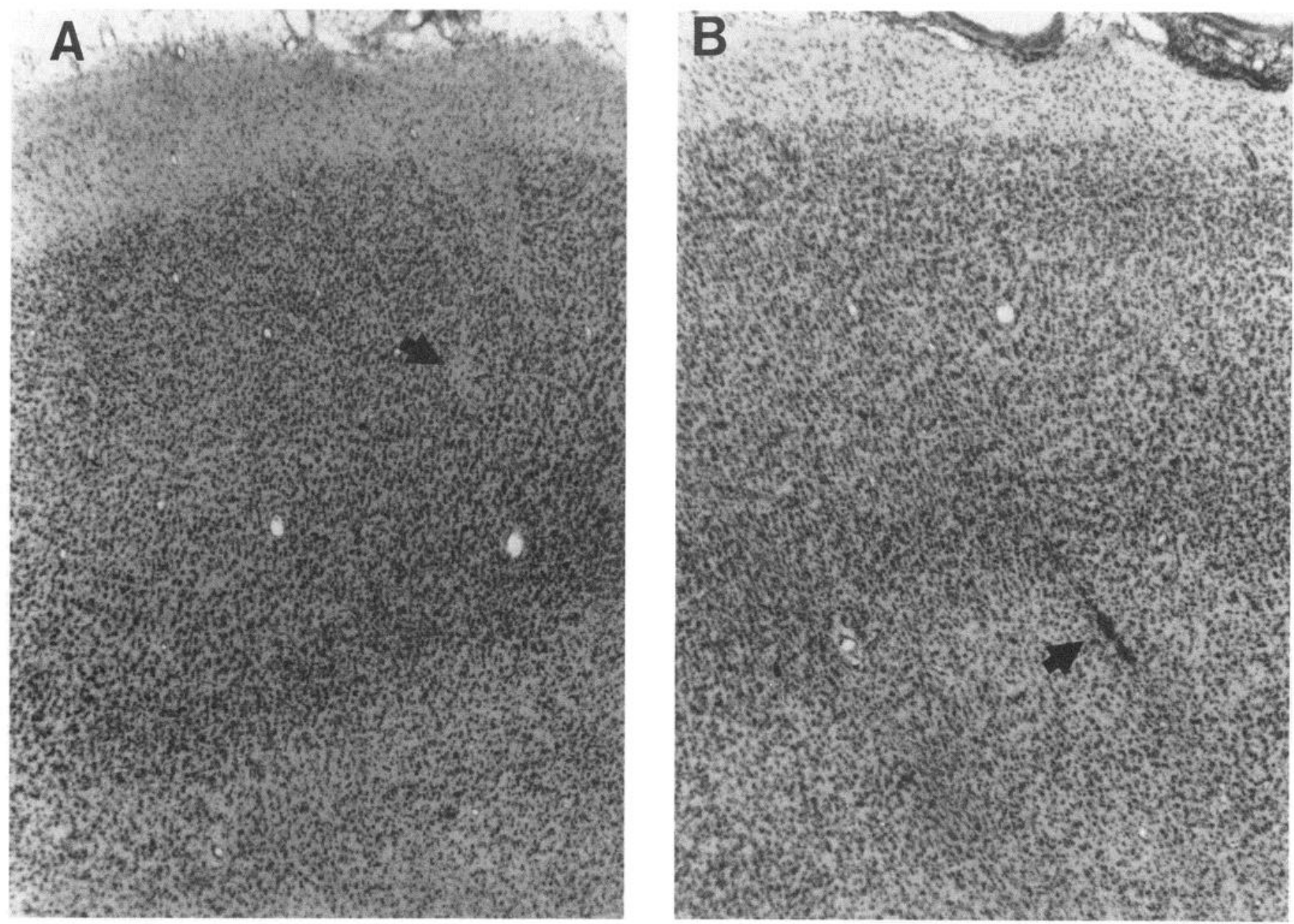

FIG. 16. A: lesion in auditory koniocortex caused by a microelectrode penetrating AI at the position marked with a circle in Fig. 14A. B: lesion in the posterior temporal plane just caudal to koniocortex at the position marked with a triangle in Fig. $14 \mathrm{~A}$. Arrows point to lesions.

described in this report were found in this cortical region as well, there were few $\mathrm{F}$ neurons and relatively many NB neurons.

\section{DISCUSSION}

\section{Spectral representation of complex sound in alert cortex}

It is of fundamental interest to know whether the topographical display of input in sensory cortex reflects primarily an organization of perceptual quality or merely a parsimonious packing arrangement of input fibers (which may still be guided by some functional principle). In the visual and somatosensory systems this question is not readily resolved because fiber-packing geometry in these afferent pathways coincides with a topographic organization of perceptual space-the parameter roughly displayed over the cortical surface. In the auditory system it seems clearer that the determinant for cortical topography is better explained by fiber packing. If there was a perceptual correlate for the tonotopic organization in the auditory system, it would be pure tone pitch. There was no indication that auditory cortex neurons were selective to a combination of stimulus parameters that might be relevant for the perception of pitch. No selectivity for combinations of harmonic components was observed, and there was no hint that any of these cells might receive the output of a periodicity detector at lower levels. Untrained humans have difficulty in distinguishing pure and complex tones, whereas pitches are readily identified irrespective of tone complexity. Tonal pitch is not yet known to be topographically displayed in auditory cortex or anywhere else in the auditory system. In a recent neuromagnetic study of human auditory cortex, Pantev et al. (1989) have claimed that "tonotopic organization of primary auditory cortex reflects the pitch rather than the frequency of the stimulus." They did not, however, show that they were monitoring primary cortex. Furthermore, they used a narrowband noise to mask the missing fundamental. This noise was almost certainly changed when the test tone was switched on and off and could thus produce a neuromagnetic response. Finally, it is unlikely that the human AI organization is radically different from that of another primate for whom we present more direct evidence here. In monkey AI it is certain that the topographic organization follows the spectral composition of 
sound that is, of course, a direct reflection of the basilar membrane innervation pattern. The topographically displayed sound spectrum does not have a simple perceptual correlate. Sounds with different spectra can, of course, be distinguished along several dimensions, but there is no indication that any such dimension corresponds to a topographic organization of the cortical surface. Strictly speaking, the organization of the auditory cortex and lower stations is not tonotopic but "cochleotopic."

\section{Neuron classes}

Because cortex represents a relatively high station in the auditory pathway, neural signals representing sound would be expected to be refined by processing within or before the cortex. The only refinement in the response patterns of alert cortical neurons reported here relates to spectral properties of sound, and the neuron classes described illustrate how the spectra of simple or complex sounds are represented in alert cortex.

F NEURONS. F neurons are similar to primary cochlear afferents (cf. Evans 1975) as they increase their frequencyresponse bandwidth monotonically with intensity. A quantitative comparison with cochlear primaries was not possible because the fine structure of tuning curves would have to depend on response averaging for which we would need more recording time than available, and on a wider range of pure-tone intensities that were not available in our preparation in which free-field sound delivery with minimal distortion was required. Dynamic ranges of $F$ neurons may, however, sometimes be wider than for primaries, and the tail portion of tuning curves so characteristic for cochlear afferents may not be well developed in F neurons, as reported in the anesthetized cat stimulated through a sealed sound system (Phillips et al. 1985). Nevertheless, it is interesting that the spectral specificity of cochlear output fibers remains relatively unchanged through five stations of the auditory pathway [including the anteroventral cochlear nucleus (AVCN), the medial and lateral superior olivary nuclei (MSO, LSO), the inferior colliculus (IC), the medial geniculate body (MGB), and the AI]. Thus the cortex has access to a relatively pure representation of low-level sensory input. At all these stations there appear to be units without inhibitory sidebands (Aitkin et al. 1975; Evans and Nclson 1973; Guinan et al. 1972; Irvine 1986; Phillips and Irvine 1981; Ryan and Miller 1978). Response areas for cochlear afferents have not been mapped with low-component harmonic complexes. It seems clear, however, that they should respond essentially like $F$ neurons.

QF NEURONS. QF response patterns should permit a classification as $F$ neurons if the reduced complex-tone response range could be explained by mechanisms other than frequency-specific lateral inhibition. If the complex-tonerange reduction is due to a weak lower frequency inhibitory sideband, however, these cells might be related to $F_{0}$ neurons. It would be interesting to know if the relative reduction of the low-fundamental frequency range displayed in complex-tone responses of QF neurons can also be observed in some cochlear afferents. This would argue against the necessary involvement of low-frequency inhibitory sidebands. Combination of two-tone suppression (cf. Evans 1975) in a number of converging cochlear afferents with different thresholds could also be involved. An inclusion of all QF neurons into the F-neuron group would lead to the important conclusion that the majority of neurons recorded in the alert auditory cortex, certainly a majority in AI, has F characteristics. Because the spectral selectivity of F neurons is highly intensity dependent, it may therefore be questioned how important frequency selectivity is for AI function. There are, however, three neuron classes with greater frequency-resolving power, the HRF, NB, and $F_{0}$ neurons. In all three, a high-frequency resolution is maintained over a wide-intensity range.

HRF NEURONS. HRF neurons can resolve narrow frequency bands, although they are not selective for them because they respond to wideband stimuli as well. Generally, distinction of sounds on the basis of spectral fine structure [for example, vowels on the basis of formants (Flanagan 1972), musical instruments, or voices on the basis of their timbre] would depend on such frequency selectivity without response suppression by broadband stimulation. Components of harmonic complexes might be read out from an array of HRF neurons and thus provide the estimate of component frequencies required by several theories on pitch perception (Goldstein 1973; Terhardt 1972; Wightman 1973) during listening in the "synthetic mode" (Terhardt 1972) (when the complex is heard as one unified sound with one pitch). Also the perceptual identification of components in the "analytic" mode (Terhardt 1972) of listening (when components are individually hcard as tones in a chord) may depend on HRF neurons. Up to seven harmonics could be distinguished in the HRF responses, and lower harmonics are resolved with greater security. Trained human subjects can typically hear out the first sixth to eighth partials of a harmonic complex, resolving lower components better (Plomp and Mimpen 1968). There is also a qualitative correspondence in intensity dependency: neural resolution tended to deteriorate with intensity, being observable over some $10-50 \mathrm{~dB}$. Humans can resolve components of complex tones up to levels of 80 dB SPL, with performance deteriorating at higher levels (Pick 1977; Scharf and Meiselman 1977). It is possible that the smaller intensity range for component resolution in HRF neurons corresponds to a poorer pure-tone (Sinnott et al. 1987) and formant (Sinnott and Kreiter 1986) frequency discrimination in monkeys as compared with humans, although peripheral filter functions estimated by psychophysical tuning curves are comparable in humans and monkeys (Serafin et al. 1982). It is interesting that the resolving power displayed by neither HRF neurons nor psychophysical observations matched that observed in the cochlear nuclei $(\mathrm{CN})$ of cats. AVCN cells can resolve up to 13 harmonics (Smoorenburg and Linschoten 1977), and narrowly tuned dorsal cochlear nucleus (DCN) neurons respond to comb-filtered noise (with sinusoidally shaped spectral peaks at locations of a harmonic series) over a 100-dB dynamic range (Evans 1977), whereas the corresponding dynamic range for auditory nerve fibers is $30-40$ 
dB. Humans attribute a "repetition pitch" (Bilsen 1966) to comb-filtered noise, provided there is a minimum peak-tovalley ratio that is almost constant when the overall amplitude of the noise is changed from 30 to $120 \mathrm{~dB}$ SPL (Bilsen and ten Kate 1977; Bilsen and Ritsma 1970). It is an open question if the cat's superior $\mathrm{CN}$ resolving power exists in primates with less well-differentiated CN (Moore 1980) in their more "encephalized" auditory system (Heiman-Patterson and Strominger 1985).

$F_{0}$ NEURONS. $F_{0}$ neurons, which are tuned similarly well to fundamentals of complexes and pure tones, are not nearly as narrowly tuned as HRF neurons. Their tuning is, however, also relatively stable with changing intensity, which suggests that they may also signal an important spectral attribute of complex sounds. In contrast to F, QF, and HRF neurons, sound energy falling into their excitatory band will not always excite these neurons. Wideband stimuli covering both excitatory and inhibitory bands may in fact be ineffective. Thus these cells are particularly suited to detect contrasts. They are maximally responsive if there is no sound energy in the low-frequency inhibitory band with all stimulus components occurring at higher frequencies. To some extent, this property is analogous to the contrast sensitivity of simple cells in visual cortex (Hubel and Wiesel 1962). We have also seen two neurons with upper inhibitory sidebands, indicating that the inverse of the $F_{0}$ spectral-contrast sensitivity exists as well. Neurons sensitive to either upper or lower spectral-contrast edges have been found relatively rarely, which would be plausible if such responses were not characteristic for AI.

NB NEURONS. NB neurons displayed similarly sharp tuning as HRF neurons. A fundamental difference is that they are silenced by wideband stimuli because of inhibitory sidebands. There are two possible interpretations for the response decline at higher intensities: 1) the BF may shift with stimulus intensity as BFs for low-frequency cochlear afferent fibers do (cf. Evans 1975), or 2) the bandwidth of the inhibitory sideband may increase with stimulus intensity [as it does for certain narrowly tuned units in auditory cortex of bats (Suga and Tsuzuki 1985) and cats (Phillips et al. 1985)]. Because the area under the FH curve is usually reduced with increasing intensity in NB neurons, the second of the two mechanisms seems to be involved, perhaps in addition to the first one. It is not certain to which extent the high proportion $(65 \%)$ of cells with "narrow" tuning described in alert squirrel monkey cortex (Pelleg-Toiba and Wollberg 1989) corresponds to NB or HRF neurons because no wideband stimuli were used to define them. A NB neuron might result from a combination of outputs from $F_{0}$ cells and units with high-frequency inhibitory sidebands. It is, however, also noteworthy that they are similar to type II neurons in the DCN (Shofner and Young 1985; Young and Voigt 1982), which are thought to be local inhibitory interneurons (Voigt and Young 1980). Because NB cells are silenced by broad-band complexes, they can hardly contribute to identification of complex sound properties including pitch or formant specification. These cells might evaluate the spectral purity of a sound. NB neurons have only been found in the lowest frequency range. This may be merely a coincidence because the sample is small. The need for spectral sharpening may, on the other hand, be greatest in the lowest frequency range where peripheral tuning curves are widest (cf. Evans 1975).

WB NEURONS. For WB cells an increase in stimulus bandwidth was more effective than an increase in puretone amplitude. It is easy to see how convergence of many normally tuned cells could produce such a response pattern if each input would be below threshold. Type IV cells in the DCN of the unanesthetized cat also respond better to noise than to pure tones (Young and Brownell 1976); however, it is unlikely that these cells represent the input for cortical WB neurons because type IV cells are excited by low-level CF tones and inhibited at higher levels (Shofner and Young 1985). No such contrast was seen for cortical WB neurons.

All neuron classes observed could be modelled by various combinations of cochlear afferent filter functions with varying inhibitory sidebands (Tomlinson 1989). The cellular elements necessary for sideband inhibition are certainly present in auditory cortex where inhibitory postsynaptic potentials (IPSPs) have been observed (de Ribaupierre et al. 1972) and an abundance of GABAergic cells has been demonstrated (Houser et al. 1984). Sideband inhibition is, however, also present at lower levels in the auditory pathway including the DCN, the IC, and the MGB (Irvine 1986). It is uncertain to what extent binaural inhibition, present at all levels of the auditory CNS (Aitkin and Webster 1972; Guinan et al. 1972; Roth et al. 1978; Tsuchitani 1988a,b), can also contribute to sidebands.

Lateral inhibition has also been reported for $30 \%$ of neurons in the squirrel monkey auditory cortex (Shamma and Symmes 1985) with upper, lower, or both upper and lower sidebands being observed (type A units). Twenty percent (type $C$ cells) displayed no sideband inhibition and are thus similar to $F$ neurons. Type A might include our classes of $F_{0}$ and NB. A direct comparison may, however, be unwarranted because in the squirrel monkey study the possibility of binaural inhibitory interaction was ruled out by monaural stimuli, and the excitatory and inhibitory tones were staggered in time to maximize inhibitory interaction, whereas our tones were always presented simultaneously and binaurally (free field).

\section{Cortical processing of complex sounds}

All spectral characteristics of complex sounds may be encoded by a complete array of neurons with very narrow tuning curves. It may be asked, therefore, why there are so many different neuronal pure-tone response bandwidths in auditory cortex. Simple interpretations would be that not all neuron classes participate in spectral sound analysis or that different neuron classes represent different stages in computational hierarchy. One might also follow Marr's (1980) logic for spatial resolution in the visual cortex and suggest that there should be parallel arrays of units with different bandwidths to guarantee fast and cconomic processing: overall frequency ranges would be estimated by broadly tuned neurons whereas fine detail would depend on narrow tuning curves, just like large and small retinal 
receptive fields would be required in visual cortex to process large contours containing small shapes. Existence of both broadly and narrowly tuned cortical units has also been reported in the alert chinchilla (Tomlinson et al. 1986) and alert cat (Goldstein et al. 1968).

It seems not unreasonable to expect neural structures specialized to process harmonic complexes. Musical pitch is defined in a harmonic framework, and pitch theories have been proposed in which stimuli are matched to some internal representation of harmonic (Goldstein 1973; Wightman 1973) or subharmonic (Terhardt 1972) series. Voiced vocalizations including human vowels (Flanagan 1972) and monkey calls (Green 1975; Rowell and Hinde 1962; Winter et al. 1966) are harmonically structured. Yet, there is no evidence for neurons selective for harmonically related components of complexes, just as there is no certainty about neuronal selectivity for specific primate vocalizations (Glass and Wolberg 1979; Mueller-Preuss 1986; Newman and Lindsley 1976; Newman and Wolberg 1973; Winter and Funkenstein 1973). Neurons in field L of the trained mynah have been reported to discriminate between vowels (Langner et al. 1981). The only convincing evidence for the expected kind of combination sensitivity has been reported by Suga and his collaborators (Suga et al. 1979, 1983; Suga and Tsuzuki 1985; Tsuzuki and Suga 1988) who described neurons in the echolocating mustache bat's cortex that are selective for combinations of a harmonic component of the echolocation call and the doppler-shifted echo of a different component. These neurons are often not selective for harmonically related components of a complex but rather for a specific deviation from the harmonic relationship that is used by the bat to locate its prey. It is further noteworthy that such combination-sensitive neurons have not been found in the bat's AI but in specialized areas located some distance away from AI. It may, therefore, prove fruitful to look for combination-sensitive neurons at some distance from $\mathrm{AI}$ in primates.

A variety of amplitude-modulated (AM) sounds have also been used to characterize cortical neurons. A sinusoidally AM pure tone, for example, has a spectrum of three harmonically related components. Neurons responding optimally to certain AM frequencies (Schreiner and Urbas 1988) cannot, however, be considered to be combination sensitive to stimulus patterns relevant for pitch because tuning to modulation frequencies was poor, limited to frequencies $<100 \mathrm{~Hz}$, and not related to the neuron's puretone BFs. Similar arguments hold for sensitivity to AM frequencies observed in field $L$ of the forebrain of mynahs (Hose 1987). There was also no relationship between cat cortical-unit sensitivity to periodically interrupted noise and the unit's CF (Kiang and Goldstein 1959). Further, no selectivity was observed for certain click repetition rates, although cortical neurons could respond to clicks up to $1,000 \mathrm{imp} / \mathrm{s}$ (Goldstein et al. 1971; de Ribaupierre et al. 1972). Thus studies concentrating on sound periodicity have also failed to detect any neuronal selectivity for harmonic complexes. A conclusion of the present investigation on spectral properties is that such selectivity is not likely to be found in AI. Its existence elsewhere is, however, not excluded.
There is good reason to believe that complex-tone analysis depends on cortical function. Although simple frequency discrimination appears to be spared after cortical lesion (Elliot and Trahoitis 1972), monkeys cannot discriminate between different types of their "coo" vocalizations after superior temporal gyrus lesion even if cortical deafness (threshold shifts) had been compensated by amplification and equalization (Heffner and Heffner 1989). Monkeys with auditory cortex defects also cannot discriminate between interrupted noise at low- $(10-80 \mathrm{~Hz})$ and high-repetition rates $(300 \mathrm{~Hz})$ (Symmes 1966). Cats trained to discriminate the missing fundamental lost that ability after extensive auditory cortex lesions (Whitfield 1980), and perception of the missing fundamental is also impaired in human patients with surgical ablation of Heschl's gyri (Zatorre 1988). If arrays of combination-sensitive neurons suitable for such complex sound processing cannot be found in cortical fields other than those explored in our study, pitch perception and similar skills might depend on large-scale parallel processing of response patterns of the kind described here. A theory proposing how that might work would still have to be formulated.

We thank Dr. Donald Greenwood, Dr. Dennis Phillips, Dr. Judy Manley-Toronchuk, and Dr. Fred Doujak for their constructive comments on earlier drafts of this paper, Dr. Irmgard Schwarz for advice on cytoarchitectonic localization of electrode tracks, and E. To for excellent technical assistance.

Sound-generating equipment was funded by the Lions MD-19 Hearing Foundation.

This work was supported by the Medical Research Council of Canada and the British Columbia Medical Services Foundation.

Address for reprint requests: D.W.F. Schwarz, University of British Columbia, A.C.U., 2211 Wesbrook Mall, Rm. F153, Vancouver, British Columbia, V6T 2B5, Canada.

Received 26 June 1989; accepted in final form 5 March 1990.

\section{REFERENCES}

AITKIN, L. M. AND WEBSTER, W. R. Medial geniculate body of the cat: organization and responses to tonal stimuli of neurons in ventral division. J. Neurophysiol. 35: 365-380, 1972.

Aitkin, L. M., Webster, W. R., Vealf, J. L., and Crosby, D. C. Inferior colliculus. I. Comparison of response properties of neurons in the central, pericentral and external nuclei of adult cat. J. Neurophysiol. 38: 1196-1207, 1975.

American Standards Association. Acoustical Terminology SI. New York: American Standards Association, 1960.

BILSEN, F. A. Repetition pitch: monaural interaction of sound with the repetition of the same but phase shifted sound. Acustica 17: 295-300, 1966.

BiLSEN, F. A. AND TEN KATE, J. H. Preservation of the internal spectrum of complex signals at high intensities. In: Psychophysics and Physiology of Hearing, edited by E. F. Evans and J. P. Wilson. London: Academic, 1977, p. 193-195.

BILSEN, F. A. AND Ritsma, R. J. Some parameters influencing the perccptability of pitch. J. Acoust. Soc. Am. 47: 469-475, 1970.

DE BOER, E. On the residue and auditory pitch perception. In: Handbook of Sensory Physiology, edited by W. D. Keidel and W. D. Neff. Bcrlin: Springer-Verlag, 1976, vol. V, part 3, p. 479-583.

BRugge, J. F. AND Rfai E, R. A. Auditory cortex. In: Cerebral Cortex. Association and Auditory Cortices, edited by A. Peters and E. G. Jones. New York: Plenum, 1985, vol. 4, p. 229-271.

CYNX, J. Periodicity pitch in a species of songbird, the European Starling (Sturnus vulgaris) (Abstract). Proc. Assoc. Res. Otolaryngol. 9: 138, 1986. 
Elliot, D. N. AND Trahoitis, C. Cortical lesions and auditory discrimination. Psychol. Bull. 77: 198-222, 1972.

Evans, E. F. Cochlear nerve and cochlear nucleus. In: Handbook of Sensory Physiology, edited by W. D. Keidel and W. D. Neff. Berlin: Springer-Verlag, 1975, vol. V, part 2, p. 1-108.

EVANS, E. F. Frequency selectivity at high signal levels of single units in cochlear nerve and nucleus. In: Psychophysics and Physiology of Hearing, edited by E. F. Evans and J. P. Wilson. London: Academic, 1977, p. 185-192.

Evans, E. F. AND Nelson, P. G. The responses of single neurones in the cochlear nucleus of the cat as a function of their location and anesthetic state. Exp. Brain Res. 17: 402-427, 1973.

Flanagan, J. L. Speech Analysis, Synthesis, and Perception (2nd ed.). Berlin: Springer-Verlag, 1972, p. 444.

Galaburda, A. M. AND Pandya, D. N. The intrinsic architectonic and connectional organization of the superior temporal region of the rhesus monkey. J. Comp. Neurol. 221: 169-184, 1983.

GLASS, I. AND WOLBERG, Z. Lability in the responses of cells in the auditory cortex of squirrel monkeys to species-specific vocalizations. Exp. Brain Res. 34: 489-498, 1979.

GOLDSTEIN, J. L. An optimum processor theory for the central formation of the pitch of complex tones. J. Acoust. Soc. Am. 54: 1496-1516, 1973.

Goldstein, M. H., Hall, J. L., AND ButTerfield, B. O. Single-unit activity in the primary cortex of unanesthetized cats. J. Acoust. Soc. Am. 43: 444-455, 1968.

Goldstein, M. H., De RibaupierRe, F., And Yeni-Komshian, G. Cortical coding of periodicity pitch. In: Physiology of the Auditory System. A Workshop, edited by M. Sachs. Baltimore, MD: National Educ. Consultants, 1971 , p. 299-305.

GREEN, S. Variation of vocal pattern with social situation in the Japanese monkey (Macaca fuscata): a field study. In: Primate Behavior, edited by L. A. Rosenblum. New York: Academic, 1975, Vol. 4, p. 1-102.

GREENWOOD, D. D. AND MARUYAMA, N. Excitatory and inhibitory response areas of auditory neurons in the cochlear nucleus. J. Neurophysiol. 28: 863-892, 1965 .

GuinaN, J. J., GuINAN, S. S., AND NorRIS, B. E. Single auditory units in the superior olivary complex. I. Responses to sounds and classification based on physiological properties. Int. J. Neurosci. 4: 101-120, 1972.

HEFFNER, H. E. AND HEFFNER, R. S. Cortical deafness cannot account for the inability of Japanese Macaques to discriminate species-specific vocalizations. Brain Lang. 36: 275-285, 1989.

Heiman-Patterson, T. D. And Strominger, N. L. Morphological changes in the cochlear nuclear complex in primate phylogeny and development. J. Morphol. 186: 289-306, 1985.

vON Helmholz, H. On the sensations of tone as a physiological basis for the theory of music. Brunswick, FRG: Vieweg, 1862 (1 st English edition, 1897).

HOSE, B., LANGNER, G., AND SCHEICH, H. Topographic representation of periodicities in the forebrain of the mynah bird: one map for pitch and rhythm? Brain Res. 422: 367-373, 1987.

Houser, C. R., Vaugn, J. E., Stewart, H. C., Jones, E. G., And PETERS, A. GABA ncurons in the cerebral cortex. In: Cerebral Cortex, edited by A. Peters and E. G. Jones. New York: Plenum, 1984, vol. 2, p. 63-90.

Houtsma, A. J. M. AND Goldstein, J. L. The central origin of the pitch of complex tones: evidence from musical interval recognition. J. Acoust. Soc. Am. 51: 520-529, 1972.

HUBEL, D. H. AND WIESEL, T. N. Receptive fields, binocular interaction and functional architecture in the cat's visual cortex. J. Physiol. Lond. 160: 106-154, 1962.

IRVINE, D. R. F. The auditory brainstem: a review of structure and function of auditory brainstem processing mechanisms. Prog. Sens. Physiol. 7: 1-279, 1986.

KiANG, N. Y. S. AND Goldstein, M. H. Tonotopic organization of the cat auditory cortex for some complex stimuli. J. Acoust. Soc. Am. 31: 786-790, 1959

LANGNER, G. Evidence for neuronal periodicity detection in the auditory system of the guinea fowl: implications for pitch analysis in the time domain. Exp. Brain Res. 52: 333-355, 1983.

LANGNER, G., BONKE, D., AND SCHEICH, H. Neuronal discrimination of natural and synthetic vowels in field $\mathrm{L}$ of trained mynah birds. Exp. Brain Res. 43: 11-24, 1981.

MARR, D. Vision: A Computational Investigation into the Human Repre- sentation and Processing of Visual Information. San Francisco, CA: Freeman, 1980, p. 397.

MERZENICH, M. M. AND BRUGGE, J. F. Representation of the cochlear partition on the superior temporal plane of the Macaque monkey. Brain Res. 50: 275-296, 1973.

MOORE, J. K. The primate cochlear nuclei: loss of lamination as a phylogenetic process. J. Comp. Neurol. 193: 609-629, 1980.

MUELLER-PREUSS, P. On the mechanisms of call coding through auditory neurons in the squirrel monkey. Eur. Arch. Psychiatry Neurol. Sci. 236: 50-55, 1986.

Newman, J. D. AND Lindsley, D. F. Single unit analysis of auditory processing in squirrel monkey frontal cortex. Exp. Brain Res. 25: $169-181,1976$.

NeWman, J. D. AND WOLBERG, Z. Multiple coding of species-specific vocalizations in the auditory cortex of squirrel monkeys. Brain Res. 54: 286-304, 1973.

PANDYA, D. N. AND SANIDES, F. Architectonic parcellation of the temporal operculum in rhesus monkey and its projection pattern. Z. Anat. Entwicklungsgesch. 139: 127-161, 1973.

PANTEV, C., HoKe, M., LutKenhoner, B., AND LeHNERTZ, K. Tonotopic organization of the auditory cortex: pitch versus frequency representation. Science Wash. DC 246: 486-488, 1989.

Peilieg-Toira, R. AND Woli.rerg, Z. Tuning properties of auditory cortex cells in the awake squirrel monkey. Exp. Brain Res. 74: 353-364, 1989.

Penfield, W. and Rasmussen, T. The Cerebral Cortex of Man. A Clinical Study of Localization of Function. New York: Macmillan, 1950.

PFINGST, B. E. AND O'CONNER, T. A. A vertical stereotaxic approach to auditory cortex in the unanesthetized monkey. J. Neurosci. Methods 2: 33-45, 1980.

Phillips, D. P. AND IRvine, D. R. F. Responses of single neurons in physiologically defined primary auditory cortex (AI) of the cat: frequency tuning and responses to intensity. J. Neurophysiol. 45: 48-58, 1981.

Phillips, D. P., Orman, S. S., Musicant, A. D., and Wilson, G. F. Neurons in the cat's primary auditory cortex distinguished by their responses to tones and wide-spectrum noise. Hear. Res. 18: 73-86, 1985.

PICK, G. F. Comment on paper by Scharf and Meiselman. In: Psychophysics and Physiology of Hearing, edited by P. Wilson and E. F. Evans. London: Academic, 1977, p. 233-234.

Plomp, R. Detectability threshold for combination tones. J. Acoust. Soc. Am. 37: 1110-1123, 1965.

Plomp, R. AND MiMPEN, A. M. The ear as a frequency analyser. II. $J$. Acoust. Soc. Am. 43: 764-767, 1968.

de Ribaupifrre, F., Goldstein, M. H., and Yeni-Komshian, G. Cortical coding of repetitive acoustic pulses. Brain Res. 48: 205-225, 1972.

ROTH, G. L., AITKIN, L. M., ANDERSEN, R. A., AND MERZENICH, M. M. Some features of the spatial organization of the central nucleus of the inferior colliculus of the cat. J. Comp. Neurol. 182: 661-680, 1978.

Rowell, T. E. AND HINDE, R. A. Vocal communication by the Rhesus monkey (Macaca mulatta). Proc. Zool. Soc. Lond. 138: 279-294, 1962.

RYAN, A. AND MILLER, J. Single unit responses in the inferior colliculus of the awake and performing rhesus monkey. Exp. Brain Res. 32: 389-407, 1978.

SCharF, B. AND Meiselman, C. H. Critical bandwidth at high intensities. In: Psychophysics and Physiology of Hearing, edited by P. Wilson and E. F. Evans. London: Academic, 1977, p. 221-232.

SCHREINER, C. E. AND URBAS, J. V. Representation of amplitude modulation in the auditory cortex of the cat. II. Comparison between cortical fields. Hear. Res. 32: 49-64, 1988.

SERAFIN, J. V., MOODY, D. B., AND STEBbins, W. C. Frequency selectivity of the monkey's auditory system: psychophysical tuning curves. $J$. Acoust. Soc. Am. 71: 1513-1518, 1982.

Shamma, S. A. ANd Symmes, D. Patterns of inhibition in auditory cortical cells in awake squirrel monkeys. Hear. Res. 19: 1-13, 1985.

SHOFNER, W. P. AND YOUNG, E. D. Excitatory/inhibitory response types in the cochlear nucleus: relationships to discharge patterns and responses to electrical simulation of the auditory nerve. J. Neurophysiol. 54: 917-939, 1985.

SinNOTT, J. M. AND KREITER, N. A. Vowel discrimination in primates. $J$. Acoust. Soc. Am. 80, Suppl. 1: S75, 1986. 
Sinnott, J. M., Owren, M. J., And Petersen, M. R. Auditory frequency discrimination in primates: species differences (Cercopithicus, Macaca, Homo). J. Comp. Psychol. 101: 126-131, 1987.

Smoorenburg, G. Audibility region of combination tones. J. Acoust. Soc. Am. 52: 603-614, 1972.

SmoorenburG, G. F. AND Linschoten, D. H. A neurophysiological study on auditory frequency analysis of complex tones. In: Psychophysics and Physiology of Hearing, edited by E. F. Evans and J. P. Wilson. London: Academic, 1977, p. 175-183.

StebBins, W. C., GREen, S., AND Miller, F. L. Auditory sensitivity of the monkey. Science Wash. DC 153: 1646-1647, 1966.

SugA, $N$. The extent to which biosonar information is represented in the bat auditory cortex. In: Dynamic Aspects of Neocortical Function, edited by G. M. Edelman, W. E. Gall, and W. M. Cowan. New York: Wiley, 1984 , p. $315-373$.

SugA, N., O'NeILl, W. E., AND Manabe, T. Harmonic-sensitive neurons in the auditory cortex of the mustache bat. Science Wash. DC 203: 270-274, 1979

Suga, N., O'Neill, W. E., KuJiRa, K., and Manabe, T. Specificity of combination-sensitive neurons for processing of complex biosonar signals in auditory cortex of the mustached bat. J. Neurophysiol. 49: 1573-1626, 1983.

SUGA, N. AND TsuzUKI, K. Inhibition and level-tolerant frequency tuning in the auditory cortex of the mustached bat. J. Neurophysiol. 53: 1109-1145, 1985.

SYMMES, D. Discrimination of intermitten noise by Macaques following lesions of the temporal lobe. Exp. Neurol. 16: 201-214, 1966.

TerhardT, E. Zur Tonhoehenwahrnehmung von Klaengen. II. Ein Funktionsschema. Acustica 26: 187-199, 1972.

Tombinson, R. W. W. Complex Tone Processing in the Primate Brain: Behavioral and Single Unit Experiments (PhD thesis). Vancouver, Canada: University of British Columbia, 1989.

Tomlinson, R. W. W., Proeschel, U. J. L., and Schwarz, D. W. F.
Neuronal responses to tones in the auditory cortex of the alert chinchilla (Abstract). Proc. Assoc. Res. Otolaryngol. 9: 56, 1986.

TOMLINSON, R. W. W. AND SCHWARZ, D. W. F. Perception of the missing fundamental in non-human primates. J. Acoust. Soc. Am. 84: 560-565, 1988.

TsUZUKI, K. AND SUGA, N. Combination-sensitive neurons in the ventroanterior area of the auditory cortex of the mustached bat. J. Neurophysiol. 60: 1908-1923, 1988.

TSUCHITANI, C. The inhibition of cat lateral superior olive unit excitatory responses to binaural tone bursts. I. The transient chopper response. $J$. Neurophysiol. 59: 164-183, 1988a.

TSUCHITANI, C. The inhibition of cat lateral superior olive unit excitatory responses to binaural tone bursts. II. The sustained discharges. J. Neurophysiol. 59: 184-211, 1988b.

VOIGT, H. F. AND YouNG, E. D. Evidence for inhibitory interactions between neurons in dorsal cochlear nucleus. J. Neurophysiol. 44: 76-96, 1980.

WHITFIELD, I. C. Auditory cortex and the pitch of complex tones. $J$. Acoust. Soc. Am. 67: 644-647, 1980.

Wightman, F. L. The pattern-transformation model of pitch. J. Acoust. Soc. Am. 66: 1381-1403, 1973.

Winter, P. A. AND Funkenstein, H. H. The effect of species-specific vocalizations on the discharge of auditory cortical cells in the awake squirrel monkey (Saimiri sciureus). Exp. Brain Res. 18: 489-504, 1973.

WinTER, P., PlOOG, D., AND LATTA, J. Vocal repertoire of the squirrel monkey (Saimiri sciureus), its analysis and significance. Exp. Brain Res. 12: 359-384, 1966.

YOUNG, E. D. AND BROWNELl, W. E. Responses to tones and noise of single cells in dorsal cochlear nucleus of unanesthetized cats. J. Neurophysiol. 39: 282-300, 1976.

Young, E. D. AND VoIGT, H. F. Response properties of type II and type III units in dorsal cochlear nucleus. Hear. Res. 6: 153-169, 1982.

ZATORRE, R. J. Pitch perception of complex tones and human temporallobe function. J. Acoust. Soc. Am. 84: 566-572, 1988. 